\title{
The Potential Translational Applications of Nanoparticles in Endodontics
}

This article was published in the following Dove Press journal:

International Journal of Nanomedicine

\author{
Jasmine Wong \\ Ting Zou \\ Angeline Hui Cheng Lee \\ Chengfei Zhang (D)
}

Restorative Dental Sciences (Endodontics), Faculty of Dentistry, The University of Hong Kong, Hong Kong Special Administrative Region
Correspondence: Chengfei Zhang Restorative Dental Sciences (Endodontics), Faculty of Dentistry, The University of Hong Kong, Floor 3B60,

Prince Philip Dental Hospital, 34 Hospital

Road, Sai Ying Pun, Hong Kong

Tel +852-2859-037।

Fax +852-2559-9013

Email zhangcf@hku.hk
Abstract: Nanotechnology has substantially progressed in the past decades, giving rise to numerous possible applications in different biomedical fields. In particular, the use of nanoparticles in endodontics has generated significant interest due to their unique characteristics. As a result of their nanoscale dimensions, nanoparticles possess several properties that may enhance the treatment of endodontic infections, such as heightened antibacterial activity, increased reactivity and the capacity to be functionalized with other reactive compounds. Effective disinfection and sealing of the root canal system are the hallmarks for successful endodontic treatment. However, the presence of bacterial biofilms and resistance to endodontic disinfectants pose a significant challenge to this goal. This has encouraged the investigation of antibacterial nanoparticle-based irrigants and intracanal medicaments, which may improve the elimination of endodontic infections. In addition, photosynthesizer-functionalized nanoparticles could also serve as a worthy adjunct to root canal disinfection strategies. Furthermore, despite the myriad of commercially available options for endodontic obturation, the "ideal" material has yet to be conceived. This has led to the development of various experimental nanoparticle-incorporated obturation materials and sealers that exhibit a range of favourable physicochemical properties including enhanced antibacterial efficacy and bioactivity. Nanoparticle applications also show promise in the field of regenerative endodontics, such as supporting the release of bioactive molecules and enhancing the biophysical properties of scaffolds. Given the constantly growing body of research in this field, this article aims to present an overview of the current evidence pertaining to the potential translational applications of nanoparticles in endodontics.

Keywords: nanoparticles, endodontics, translational research, disinfection, obturation, regenerative procedures

\section{Introduction}

Nanomaterials are natural, incidental or synthetic materials that contain particles in unbound states, aggregates or agglomerates, and of which $50 \%$ or more of the particles possess external dimensions between $1 \mathrm{~nm}$ to $100 \mathrm{~nm}$. Nanomaterials are classified based on the dimensions, the materials used and the origin of the materials. $^{2}$ Typically, nanoparticles are comprised of three layers: the core, which is the inner portion and the main material of which the nanoparticle is made of; the shell layer, which is the intermediate layer and is chemically different from the core; and the surface layer, which is the outer layer and can be functionalized with other particles via surface interactions. ${ }^{3}$ Nanomaterials have distinct advantages in that they exhibit unique physicochemical properties when compared to their bulk counterparts due to their nanoscale sizes and high surface-area-to-volume ratio. ${ }^{2,3}$ 
This includes increased reactivity, greater solubility, biomimetic features and the ability to be functionalized with other materials such as drugs, bioactive molecules and photosynthesizers. ${ }^{3-5}$ Furthermore, antimicrobial nanoparticles can better infiltrate biofilms, are potent at smaller doses and may help mitigate the increasing use of antibiotics. ${ }^{6}$ Many antimicrobial nanoparticles possess common mechanisms of action. Nanoparticles can penetrate into biofilms and interact electrostatically with bacterial cell walls, which leads to cell membrane damage, increased cell permeability, generation of reactive oxygen species, interference with cellular functions, destruction of proteins, DNA damage and, ultimately, cell death (Figure 1). ${ }^{6-8}$

Given their many inherent benefits, the potential utilization of nanoparticles in the fields of medicine and dentistry has garnered substantial enthusiasm. ${ }^{5}$ The term "nanodentistry" was first introduced at the turn of the

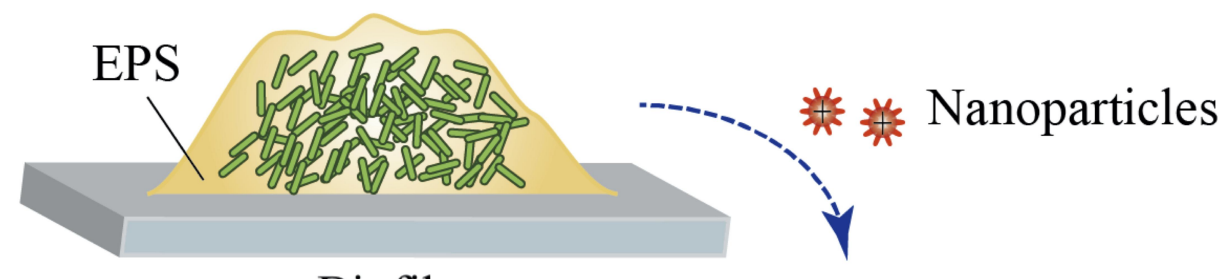

\section{Biofilm}

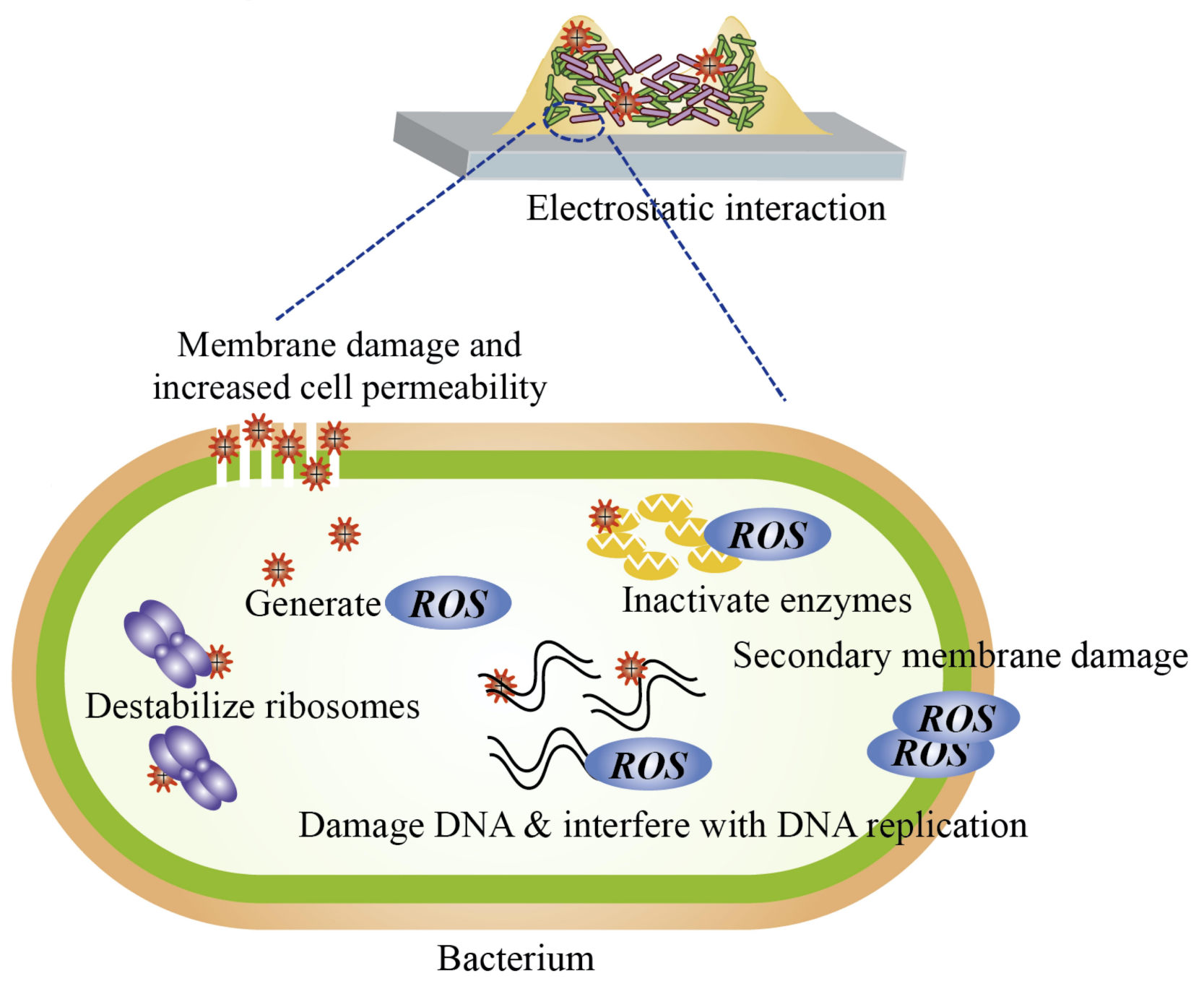

Figure I Proposed mechanisms of action of antibacterial nanoparticles. Nanoparticles penetrate biofilm and electrostatically interact with bacterial cell walls. The resultant cell wall and membrane disruption leads to increased cell permeability and leakage of the cellular constituents. Nanoparticles are also able to interfere with cellular functions, denature proteins and destabilize ribosomes. Reactive oxygen species (ROS) are produced from the membrane-nanoparticle interactions. ROS may interfere with DNA replication, cause DNA destruction, enzyme inactivation and secondary membrane damage. 


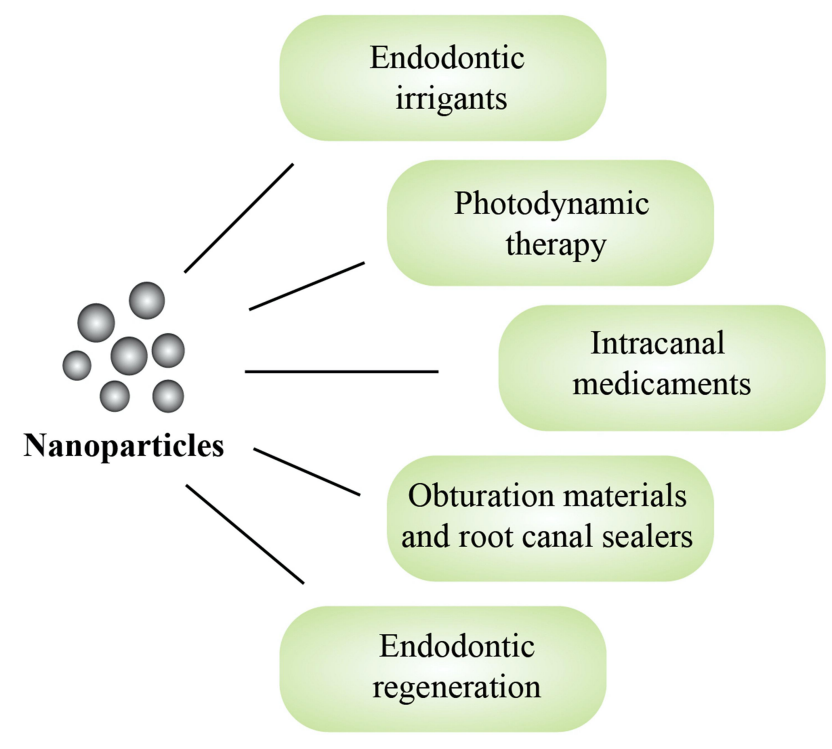

Figure 2 The potential translational applications of nanoparticles in endodontics.

$21^{\text {st }}$ century. $^{9}$ Innovative endeavours have since led to nanotechnology being incorporated into a myriad of areas in clinical dentistry, such as direct restorative materials, materials used for dental prostheses, periodontal treatment, guided tissue regeneration, modifications of implant surfaces and endodontics. ${ }^{7,10}$

Over the last decade, the use of nanoparticles in endodontics has attracted significant attention from researchers. Since its introduction, our collective understanding of this field has grown substantially, with new studies constantly adding to the existing knowledge. Hence, the aim of this review was to summarize, compile and integrate the current literature on the potential translational applications of nanoparticles in endodontics. The scope of this article encompasses an overview of the different nanomaterials used in endodontic irrigation strategies, photodynamic therapy, intracanal medicaments, obturation materials and regenerative procedures (Figure 2), as well as a summary of their advantages and limitations in the given applications.

\section{Irrigation Strategies}

The current understanding of endodontic infections suggests that microbial biofilms play a crucial role in the development and pathogenesis of apical periodontitis. ${ }^{11,12}$ Thus, effective chemo-mechanical debridement is essential in order to eliminate the root canal infection. However, biofilm bacteria benefit from a variety of factors that help enhance their survival. For example, bacteria within biofilms are protected by a self-produced matrix of extrapolymeric substance (EPS), which dampens the infiltration of root canal disinfectants and reduces their efficacy. ${ }^{13,14}$ Furthermore, anatomically minute regions in the root canal system may be inadequately debrided, resulting in residual infection. ${ }^{15}$ In addition, irrigants are often unable to reach the depths of dentinal tubules, ${ }^{16}$ permitting the persistence of bacteria, in particular Enterococcus faecalis (E. faecalis), which is commonly associated with posttreatment failure. ${ }^{17,18}$ The most commonly used endodontic irrigant is sodium hypochlorite $(\mathrm{NaOCl})$, often at concentrations ranging between $0.5 \%$ to $5.25 \% .^{19,20}$ Classic studies have regularly touted its tissue dissolving and antimicrobial properties. $^{21,22}$ However, use of $\mathrm{NaOCl}$ can have several unfavourable outcomes such as disintegration and weakening of the organic dentine matrix, ${ }^{23}$ damage to the periapical tissues ${ }^{24}$ and formation of persister bacteria. $^{25}$ Chlorhexidine has been suggested to be a less caustic endodontic disinfectant and is generally used at a concentration of $2 \%,{ }^{19}$ however its main drawbacks include the inability to degrade necrotic tissue ${ }^{26}$ and its reduced efficacy against Gram-negative microbes. ${ }^{27}$ Ethylenediaminetetraacetic acid (EDTA) is a chelating agent, often employed to remove the smear layer. ${ }^{28}$ E. faecalis biofilm was found to be more susceptible to $2.5 \% \mathrm{NaOCl}$ used in conjunction with $17 \%$ EDTA. $^{29}$ However, excessive use can lead to dentine demineralization and erosion, especially when combined with $\mathrm{NaOCl}^{30}$ Owing to the aforementioned limitations of current irrigation practices, it is no surprise that there has been an increasing interest in nanoparticle-based irrigants, particularly silver nanoparticles (AgNPs), which are the most studied to date in this field. ${ }^{31}$

\section{Silver Nanoparticles}

AgNPs have been widely investigated in dentistry. ${ }^{10}$ AgNPs exhibit both antimicrobial and antifungal properties as they possess a multi-level mode of action. By electrostatically interacting with cell membranes and binding to thiol groups of proteins, AgNPs are able to disrupt cell walls and metabolic processes, inactivate bacterial enzymes, increase cell permeability and generate reactive oxygen species. ${ }^{7,32}$ More recently, it has been shown that AgNPs could not only improve the antifungal effects of antifungal agents, but also enhance antibacterial effects of antibiotics against a range of bacteria, including antibiotic resistant strains. ${ }^{33,34}$ The synergistic and multimode antibacterial actions substantially decrease the need for high 
doses of antibiotics, therefore minimizing the potential of antibiotic resistance and toxicity to the neighbouring tissues. $^{33,34}$ On the other hand, bacteria such as Gramnegative Escherichia coli and Pseudomonas aeruginosa could quickly develop resistance to AgNPs after repetitive exposure by producing flagellin, which triggers the aggregation of the nanoparticles. ${ }^{35}$

In regard to endodontic infections, AgNPs were shown to possess antimicrobial and antibiofilm efficacy against E. faecalis. ${ }^{36-38}$ When used as an irrigating solution, poly (vinyl alcohol) (PVA) coated AgNPs were efficacious against Pseudomonas aeruginosa, Candida albicans and E. faecalis. ${ }^{39}$ Positively charged AgNPs bactericidal efficacy was not inhibited by dentine powder after 24 hours, ${ }^{36}$ whilst the antibiofilm and antimicrobial properties were found to be enhanced by ultrasonic activation ${ }^{40}$ and $\mathrm{Nd}$ : YAG laser irradiation respectively. ${ }^{41}$ Surface charge and contact time were important factors in determining its antimicrobial properties, as positively charged AgNPs had the lowest minimum inhibitory concentration and took the shortest amount of time to inhibit planktonic E. faecalis growth compared to neutral and negatively charged AgNPs. ${ }^{36}$ A study reported that AgNPs antimicrobial activity was on par with conventional endodontic irrigants such as $2 \%$ chlorhexidine, $1 \% \mathrm{NaOCl}$ and $5 \%$ NaOCl. ${ }^{42}$ Halkai et al reported that biosynthesized AgNPs had antibacterial activity against $E$. faecalis similar to that of ampicillin and $2 \%$ chlorhexidine. ${ }^{43}$ On the other hand, some studies have questioned the efficacy of AgNPs-based irrigants in comparison to conventional endodontic irrigants. AgNPs solutions were less effective at reducing viable $E$. faecalis in biofilm than $2 \%$ chlorhexidine after 5 minutes of irrigation and only equally effective after 15 minutes. ${ }^{44}$ Furthermore, $\mathrm{NaOCl}$ also exhibited superior biofilm dissolving and antibacterial properties compared to both chlorhexidine and AgNPs solutions. ${ }^{44} \mathrm{Wu}$ et al suggested the use of AgNPs may be more appropriate as an intracanal medicament due to their contact and timedependent nature, reporting that syringe irrigation of AgNPs was less effective than gel application in eliminating biofilms. ${ }^{37}$ Studies have suggested that AgNPs used in conjunction with graphene oxide may increase the stability, prevent aggregation and promote synergistic antimicrobial properties. ${ }^{40,45}$ Furthermore, nanoscale graphene oxide also has inherent antibacterial properties against common dental pathogens. ${ }^{46}$ A AgNPs-graphene oxide system was reported to successfully disrupt biofilm in an ex vivo model, however $2.5 \% \mathrm{NaOCl}$ was still superior in reducing biofilm volume and microbial cell counts. ${ }^{40}$ It is possible that the varying results of different studies could be attributed to the different formulations, characteristics and concentrations of AgNPs used, as well as dissimilar experimental conditions.

Irrigating with AgNPs solutions may influence the physical and structural properties of root dentine. Using a AgNPs-based irrigant as a final rinse almost doubled the fracture resistance of endodontically treated teeth compared to when $\mathrm{NaOCl}$ was used. ${ }^{47}$ An imidazolium-based AgNPs solution was found to increase dentine roughness, which may have implications regarding the adhesion of obturation and restorative materials to root canal walls. ${ }^{48}$ AgNPs-based irrigants did not negatively interfere with the hardness and elastic modulus of dentine ${ }^{49}$ or the bond strength and interface permeability of resin-bonded glass-fibre posts. ${ }^{50}$ However, AgNPs may be deleterious to the aesthetic outcome of endodontic treatment given their potential to stain dentinal walls and induce discolouration. ${ }^{51}$

Concerns have been raised regarding the cytotoxicity of AgNPs and their tendency to aggregate. The cytotoxic effects could be due to the production of reactive oxygen species that initiate pro-inflammatory host responses, the extent of which depends on the concentration, dimensions and aggregation of AgNPs. ${ }^{52}$ Furthermore, aggregation of AgNPs may also affect the release of $\mathrm{Ag}$ ions and hence decrease the antimicrobial efficacy. ${ }^{10}$ Stabilizing agents such as imidazole can prevent the aggregation of AgNPs and dampen the cytotoxic effects. ${ }^{53}$ Abbaszadegan et al reported that imidazolium-based ionic liquid-protected AgNPs exhibited minimal cytotoxicity. ${ }^{36}$ Gomes-Filho et al studied the tissue reactions to different concentrations of AgNPs dispersions of rats that were implanted with fibrin-filled polyethylene tubes and found that lower concentrations of AgNPs were more biocompatible. ${ }^{54}$ Another in vivo study suggested the tissue reactions of rats injected with either imidazoliumbased ionic liquid-protected $\mathrm{AgNPs}, 2.5 \% \mathrm{NaOCl}$ or $2 \%$ chlorhexidine were all comparable. ${ }^{55}$ PVA has been similarly used to stabilize AgNPs, and the resultant irrigant showed promising biocompatibility and no genotoxic effects to fibroblast cells. ${ }^{56}$ Encapsulation of AgNPs using a silica coating was found to improve the stability and prolong the antimicrobial activity of an experimental irrigant, resulting in minimal biofilm regrowth at 7 days compared to bare AgNPs which were associated with biofilm regrowth at 2 days. ${ }^{57}$ Nevertheless, before advancing to clinical studies, careful investigation into the appropriate use of AgNPs in 
endodontic therapies, as well as the potential hazards to human health and the environment, is essential. ${ }^{10,31}$

As demonstrated, numerous studies have been dedicated to investigating the translational potential of AgNPs in endodontic irrigation strategies. In order to provide sufficient context for interpretation, allow for comparison between papers and aid the assessment of potential risks, complete physicochemical characterization is important. ${ }^{58,59}$ This includes, but is not limited to, the average diameter, zeta potential, surface plasmon resonance peak and concentration. ${ }^{32,35,36,57}$ A full list of the key physicochemical properties of nanomaterials can be found in Table $1 .{ }^{59}$ For example, Abbaszadegan et al provided a comprehensive characterization of the synthesized AgNPs with negative, neutral and positive surface charges, reporting the plasmon resonance peak was $400 \mathrm{~nm}, 425 \mathrm{~nm}$ and $407 \mathrm{~nm}$, average size was 7.5 $\mathrm{nm}, 10.1 \mathrm{~nm}$ and $9.0 \mathrm{~nm}$, concentration was $9.7 \times 10^{-8}$ mol L ${ }^{-1}, 4.0 \times 10^{-8} \mathrm{~mol} \mathrm{~L}^{-1}$ and $5.7 \times 10^{-8} \mathrm{~mol} \mathrm{~L}^{-1}$ and zeta potential was $-38.0 \mathrm{mV}, 0.0 \mathrm{mV}$ and $+50.0 \mathrm{mV}$ respectively. ${ }^{36}$ Overall, it appeared that a number of studies investigating AgNPs in the context of root canal irrigation provided partial characterization and mainly stated the particle size, concentration and, if the nanoparticles were outsourced, the manufacturing companies. ${ }^{37,39-42,44,47,49-51,54,56}$ Regardless of the source of nanoparticles, whether they may be purchased from third parties or synthesized by the researchers, declaring the relevant physicochemical properties can help strengthen the scientific value of future studies on nanoparticle applications in endodontics. ${ }^{7}$

Table I Important Physicochemical Properties of Nanomaterials

\begin{tabular}{|c|c|}
\hline Physical Properties & Chemical Properties \\
\hline $\begin{array}{l}\text { - Size and size } \\
\text { distribution } \\
\text { - Shape and specific } \\
\text { surface area } \\
\text { - Agglomeration/ } \\
\text { aggregation } \\
\text { - Surface modifications } \\
\text { and topography } \\
\text { - Crystalline structure } \\
\text { - Solubility }\end{array}$ & $\begin{array}{l}\text { - Chemical composition and } \\
\text { - Suncentration } \\
\text { - Zeta potential/surface charge } \\
\text { - Reactivity (photocatalytic activity, radical } \\
\text { - formation potential, redox potential) } \\
\text { - Hydrophilicity/hydrophobicity }\end{array}$ \\
\hline
\end{tabular}

Notes: Data from the Scientific Committee on Emerging and Newly Identified Health Risks of the European Commission. ${ }^{59}$

\section{Chitosan Nanoparticles}

Chitosan is a natural, organic biopolymer derived from chitin, which can be sourced from the shells of crabs and shrimps. As chitosan is a cationic compound, it exerts its broad spectrum antimicrobial action by interacting with negatively charged bacterial cell membranes, which increases its permeability and leads to leakage of the intracellular constituents and ultimately cell death. ${ }^{60}$ Apart from its antimicrobial properties, chitosan is also biodegradable, biocompatible and has chelating abilities, making it an attractive alternative to modern root canal irrigants. $^{61}$

Chitosan nanoparticle solutions were found to possess antibacterial properties against $E$. faecalis and were able to inhibit biofilm growth. ${ }^{62,63}$ However, another study found its antibacterial efficacy may depend on the state of the bacteria, as planktonic bacteria were totally eliminated whilst their biofilm counterparts persisted after 72 hours. ${ }^{64}$ Chitosan nanoparticles were able to retain their antimicrobial properties after aging for 90 days. ${ }^{64}$ Furthermore, its bactericidal effects are time, concentration and contact-dependent. ${ }^{64,65}$ Antibacterial efficacy may be hampered by the presence of inhibitors such as pulpal remnants and bovine serum albumin, but was not affected by dentine, the dentine matrix or lipopolysaccharides (LPS) ${ }^{66}$ Conditioning the root canal surface with carboxymethyl chitosan was reported to improve disinfection and prevent bacterial adhesion to dentine prior to obturation. ${ }^{67}$ Another study found that although the antibiofilm effects were not enhanced by surface treatment with chitosan nanoparticle formulations per se, it may still provide additional structural benefits via collagen cross-linking. ${ }^{68}$ Several methods have been suggested in order to enhance the distribution and the effects of chitosan nanoparticles within the root canal system including electrophoresis, ${ }^{63}$ diode laser application, ${ }^{69}$ high-intensity focused ultrasound $^{70}$ and manual dynamic activation, which involves pumping a well-fitted gutta-percha cone in a prepared root canal to produce microbubbles and enhance fluid dynamics. ${ }^{71}$

Several studies have demonstrated chitosan's ability to act as a chelating agent and potentially improve the wettability of dentine. ${ }^{62,72,73}$ At the same time, chitosan nanoparticles showed the potential to stabilize dentine collagen by providing resistance to bacterial collagenase degradation. ${ }^{74}$ It has been suggested that conventional chelating agents remain superior in promoting sealer 
penetration, as a final rinse of $\mathrm{Qmix}^{\circledR}$ or $17 \%$ EDTA resulted in roughly double the sealer penetration depth into dentinal tubules at $5 \mathrm{~mm}$ from the apex compared to a final rinse of chitosan nanoparticles only. ${ }^{75}$ On the other hand, a recent study found that conditioning dentine with a chitosan-hydroxyapatite precursor nanocomplex prior to tricalcium silicate sealer application resulted in significantly improved mean sealer penetration into tubules. ${ }^{73}$ Coupled with its antimicrobial properties, chitosan nanoparticle solutions appear to be promising contenders for novel irrigants, ${ }^{62,76}$ although it has been suggested that the prolonged treatment time and contact-dependent nature of chitosan nanoparticle-based irrigants are limitations that warrant further research to overcome. ${ }^{64}$

\section{Other Metal and Metal Oxide Nanoparticles}

Metal oxide nanoparticles have also been investigated as potential endodontic irrigants. Zinc oxide nanoparticles (ZnONPs) have been touted for their bactericidal properties, with a mechanism of action similar to that of AgNPs. ${ }^{6}$ A ZnONPs-based irrigant was found to eliminate planktonic E. faecalis and disrupt the biofilm matrix, whilst retaining its antibacterial activity after 90 days of aging. ${ }^{64}$ However, its antibacterial efficacy was less pronounced against biofilm bacteria compared to their planktonic equivalents. ${ }^{64} \mathrm{~A}$ combination of AgNPs and ZnONPs in a polymeric solution showed superior antimicrobial activity against $E$. faecalis compared to when each was used independently, although $2.5 \% \mathrm{NaOCl}$ was still more effective in reducing colony forming units (CFU). ${ }^{31}$ A study reported that a ZnONPs-based solution exhibited weaker antimicrobial efficacy against $E$. faecalis compared to $2 \%$ chlorhexidine and $5 \% \mathrm{NaOCl}$, however the result was not statistically significant. ${ }^{42}$ Its use as a final irrigant resulted in an approximately $400 \mathrm{~N}$ greater mean fracture resistance of root canal treated teeth compared to when $\mathrm{NaOCl}$ was used. ${ }^{47}$ On the other hand, another study reported the push-out bond strength of endodontic sealers was negatively affected following irrigation with a polymeric suspension containing AgNPs and ZnONPs, possibly due to the deposition of nanoparticles on the dentine surface which decreased sealer adhesion. ${ }^{77}$

Magnesium oxide, titanium dioxide and iron oxide likewise exhibit antimicrobial properties, ${ }^{6,78}$ albeit the body of research on these compounds as potential endodontic irrigants is comparably less. Monzavi et al found that a nano-magnesium oxide solution had long-term antimicrobial efficacy in both in vitro and ex vivo environments against . $_{\text {faecalis. }}{ }^{78}$ Using a titanium dioxide nanoparticle solution as a final rinse was found to result in double the mean fracture resistance of endodontically treated teeth compared to when $\mathrm{NaOCl}$ was used. ${ }^{47}$ Iron oxide nanoparticles exhibited peroxidase-like activity when synthesized into an irrigating solution with hydrogen peroxide, resulting in antibiofilm and bactericidal activity against E. faecalis. ${ }^{79}$ However, like AgNPs, metal and metal oxide nanoparticles may also possess a degree of cytotoxicity, hence risk assessment and biocompatibility studies are paramount before proceeding to in vivo research. $^{6}$

Lastly, gold nanoparticles have been reported to be a promising nanomaterial with substantial biomedical applications. ${ }^{80}$ However, they have not been as commonly investigated for their use in endodontics, possibly due to reservations regarding their antimicrobial efficacy. ${ }^{6,31,41}$ Kushwaha et al evaluated the effect of AgNPs and gold nanoparticle-based irrigants on microbial eradication in teeth inoculated with E. faecalis, with or without $\mathrm{Nd:}$ YAG laser activation. Whilst Nd:YAG laser activation did improve the antimicrobial activity of gold nanoparticles, the use of AgNPs still resulted in significantly lower mean CFU. ${ }^{41}$ However, gold nanoparticles have been shown to exhibit antibacterial properties in other contexts such as in burn wound infections, ${ }^{81}$ possibly due to differences in the microbiological composition and the presence of more susceptible pathogens compared to that of root canal infections.

Overall, research into nanoparticle-based irrigants may pave the way for novel and innovative endodontic disinfection strategies. Further studies are needed to fully elucidate the potential of various nanomaterials to be utilized as endodontic irrigants. Furthermore, studies should aim to investigate the methods of nanoparticle incorporation into irrigation solutions, their long-term antibacterial action and in vivo efficacy, whilst minimizing any potential negative or adverse effects. ${ }^{7}$

\section{Photodynamic Therapy}

Photodynamic therapy involves the combination of light and photosynthesizers to induce photochemical reactions. Light of specific wavelengths is used to activate the photosensitizers which produce reactive oxygen species and cause cytotoxic effects to the target cells. ${ }^{82}$ More recently, studies have been dedicated to exploring disinfection 
strategies employing functionalized nanoparticles in conjunction with photodynamic therapy in order to enhance the antibacterial efficacy, encourage irrigant delivery and improve the physical properties of dentine. The antimicrobial properties of nanoparticles combined with the oxidative abilities of photosynthesizers, such as methylene blue, rose bengal and indocyanine green, could give rise to synergistic effects. ${ }^{83-85}$ Although several limitations exist, such as the potential of aggregate formation of these compounds and possible difficulties in infiltrating into the complex anatomical spaces, ${ }^{86,87}$ further research in this area may help optimize the potential of these novel disinfection modalities.

Rose bengal-conjugated chitosan has been investigated for its antimicrobial potential in several studies by Shrestha and co-workers with promising results. It was found to not only exhibit antibiofilm properties but also low levels of cytotoxicity. ${ }^{85}$ Photoactivated rose bengalconjugated chitosan nanoparticles were also able to inactivate endotoxins. ${ }^{88,89}$ In the presence of tissue inhibitors, these functionalized nanoparticles showed a $50 \%-65 \%$ reduction in planktonic E. faecalis, whereas when coupled with photoactivation, it resulted in complete elimination of the microorganisms after 24 hours. ${ }^{90}$ Chitosan has also been used in conjunction with methylene blue. Photodynamic activation of chitosan with methylene blue showed superior antibacterial action against $E$. faecalis in infected root canals compared to chitosan or methylene blue alone, although the differences were not statistically significant. ${ }^{84}$ Indocyanine green, a photosynthesizer that has recently gained more attention, was investigated in conjunction with AgNPs and laser activation. This combination was able to produce a $99.12 \%$ reduction in CFU counts of E. faecalis, which was higher than the $\mathrm{CFU}$ reduction for diode laser alone and AgNPs alone, albeit not statistically significant. ${ }^{83}$ Another study reported that nano-graphene oxide was able to act as a photosynthesizer carrier and enhance the bioavailability and stability of indocyanine green. ${ }^{91}$ Photoactivation of indocyanine green incorporated into nano-graphene oxide resulted in 1.3 times greater antibiofilm efficacy compared to photoactivation of indocyanine green alone. ${ }^{91}$

Another benefit of the application of nanoparticles with photosynthesizers is the potential to improve the physical properties of root dentine. Much of the attention has been placed on chitosan nanoparticles decorated with rose bengal as multiple studies have shown its potential to enhance dentine properties. ${ }^{92-94}$ Photodynamic activation of rose bengal was able to enhance collagen cross-linking and simultaneously facilitate chitosan nanoparticle binding to collagenase, which inhibited collagenolytic activity. ${ }^{94}$ Its application has been found to enhance the dentine fatigue resistance, ${ }^{92}$ nanohardness and modulus of elasticity. ${ }^{93}$ Hence, these synergistic actions may help reinforce the structural integrity of weakened dentine. ${ }^{94}$

\section{Intracanal Medicaments}

An intracanal medicament is an antibacterial dressing that is placed during multiple-visit endodontic treatment to aid the disinfection of the root canal system. Calcium hydroxide is a frequently used intracanal medicament in modern endodontics due to its proven antibacterial properties. ${ }^{95,96}$ However, the evidence has since called into question the efficacy of calcium hydroxide against recalcitrant endodontic infections. ${ }^{18,65,97}$ Prolonged placement may also result in weakening of the root structure. ${ }^{98}$ Other medicaments such as triple antibiotic pastes have emerged as an alternative, particularly for regenerative endodontic procedures, although some guidelines challenge the evidence supporting its routine use, especially given the risks of antibiotic resistance. ${ }^{99}$ All in all, the quest for the ideal intracanal dressing continues with researchers turning towards nanoparticles as a potential area of further innovation and development.

\section{Calcium Hydroxide Nanoparticles}

Calcium hydroxide nanoparticles may possess several advantages over their conventional counterparts, such as improved depth of penetration, increased surface area contact with pathogens, superior solubility and greater antimicrobial activity. ${ }^{100-102}$ Several studies have found that nano-calcium hydroxide showed deeper penetration into dentinal tubules and had superior antibacterial activity against E. faecalis compared to conventional calcium hydroxide. ${ }^{100-103}$ Furthermore, nano-calcium hydroxide resulted in less reduction of dentine microhardness compared to conventional calcium hydroxide dressing. ${ }^{104}$ Conventional calcium hydroxide also resulted in a greater decrease in fracture resistance compared to the application of their nanosized counterparts. ${ }^{101}$ Cytotoxicity, on the other hand, was found to be greater for nano-calcium hydroxide compared to conventional calcium hydroxide, although this finding was not statistically significant. ${ }^{105}$ 


\section{Antimicrobial Nanoparticles}

Apart from calcium hydroxide, other types of antimicrobial nanoparticles, such as AgNPs and chitosan, have been incorporated or formulated into novel intracanal medicaments. It has been reported that the delivery method and duration of placement of nanoparticles were important factors that affected antimicrobial potential. ${ }^{37}$ For example, AgNPs exhibited better antibiofilm properties as medicaments rather than irrigants. ${ }^{37}$ Longer periods of dressing may lead to better effects, as a 4-week placement resulted in approximately $25 \%$ greater proportion of dead cells in E. faecalis biofilm compared to placement for 2 weeks. ${ }^{106}$ Application of a chitosan nanoparticle-based medicament resulted in appreciable antimicrobial properties and was less detrimental to dentine strength compared to calcium hydroxide, likely due to the promotion of collagen cross-linking and the neutralizing effect on matrix metalloproteinases. ${ }^{101}$ However, the same study found that the depth of sealer penetration into dentinal tubules may be compromised due to chitosan's tendency to agglomerate. ${ }^{101} \mathrm{~A}$ study compared the antimicrobial efficacy of nanoparticulate chitosan and poly(lactic-coglycolic) acid (PLGA) employed as potential intracanal antibiotic delivery agents, with the latter exhibiting better sustained antimicrobial effects over 2 weeks. ${ }^{107}$

Intracanal dressings require certain physical and chemical properties to allow them to remain in the root canal system whilst ideally maintaining a certain level of antimicrobial activity. These properties can be affected by the choice of vehicle. ${ }^{108}$ Hydroxyethylcellulose, polyethyleneglycol and carbomer were evaluated as vehicles for AgNPs, and whilst all resulted in stable formulations, hydroxyethylcellulose had the most promising properties such as homogeneity, fluidity and antimicrobial efficacy. ${ }^{109}$ On the other hand, a AgNPs-methylcellulose gel was found to have limited antifungal effects compared to calcium hydroxide and $2 \%$ chlorhexidine gel. The authors suggested potential reactions between the carrier and AgNPs may have been responsible. ${ }^{110}$ Another study also implicated the limitations of viscous carriers in allowing diffusivity of nanoparticles, as ZnONPs gels, with or without AgNPs, eliminated significantly less E. faecalis compared to when calcium hydroxide and chlorhexidine were used. ${ }^{111}$ The study called for further research to evaluate the different formulations of nanoparticle-based intracanal medicaments to optimize their disinfecting abilities and minimize interferences between the materials. ${ }^{111}$

\section{Combination of Antimicrobial Nanoparticles and Calcium Hydroxide}

Studies have explored the concept of incorporating nanoparticles to improve the properties of existing medicaments, particularly calcium hydroxide. It has been suggested that combining calcium hydroxide and antimicrobial nanoparticles together may encourage synergistic effects, collectively resulting in enhanced antimicrobial properties. ${ }^{91}$ When AgNPs were added to calcium hydroxide, the antimicrobial activity of this combination was more effective than calcium hydroxide, with or without chlorhexidine, and AgNPs alone, ${ }^{112-114}$ but not significantly different to that of triple antibiotic paste. ${ }^{106}$ Balto et al remarked on the time-dependent nature of these novel intracanal medicaments, suggesting long-term contact improved the antibiofilm efficacy. ${ }^{106}$ Furthermore, no significant colour change of dentine was observed in several studies. ${ }^{106,115}$ It has also been reported that the combination of calcium hydroxide and ZnONPs exhibited higher antimicrobial efficacy compared to ZnONPs alone. ${ }^{116}$ Another study found that the antimicrobial properties of this pairing was further enhanced by the addition of chlorhexidine. ${ }^{117}$

\section{Porous Calcium Silicate and Bioactive Glass Nanoparticles}

The interest in nanoparticulate calcium silicate compounds with internal porous structures stems from their bioactive, biocompatible and osteogenic properties, as well as their potential to act as drug carriers. ${ }^{118}$ Porous calcium silicate nanospheres were able to infiltrate dentinal tubules and enhance mineralization, setting up a promising foundation for the development of novel intracanal dressings. ${ }^{118}$ With the addition of AgNPs, mesoporous calcium silicate nanoparticles showed sustained release of Ag ions and inhibited E. faecalis colonization. ${ }^{119,120}$ Other studies found the combination of AgNPs and nano-zinc with mesoporous calcium silicate nanoparticles exhibited good antibiofilm efficacy, minimal cytotoxicity, ${ }^{121}$ sustained ion release, dentinal tubule infiltration and negligible changes to the mechanical properties of dentine. ${ }^{122}$ The substantivity of these compounds may be attributed to the mesoporous structure which allows these compounds to carry antimicrobial nanoparticles and support their sustained release. ${ }^{120,123}$ Bioactive glasses also possess antibacterial properties due to their ability to transform the alkalinity of the environment. ${ }^{124}$ Waltimo et al found that 
nanoparticulate bioactive glasses released more alkaline species and hence had greater antibacterial activity compared to their micron-sized equivalents. ${ }^{124}$ However, this alkalinity may have an impact on the physical properties of dentine as a study reported the application of nanoparticle bioactive glasses resulted in a $20 \%$ decrease in flexural strength compared to the saline control, although not statistically significant. ${ }^{125}$ Given that radiopacity is an important characteristic of endodontic sealers, nanosized bioactive glasses were modified with bismuth oxide to improve radiopacity whilst maintaining bioactive capacity. ${ }^{126}$ Apart from their potential use as intracanal disinfectants, several authors have also advocated the development of calcium silicate nanoparticles into novel root canal sealers due to the aforementioned benefits. $^{121,122,126}$

\section{Obturation Materials and Root Canal Sealers}

Subsequent to adequate cleaning and shaping, it is important to seal the root canal system in order to prevent the ingress of bacteria and reduce the risk of re contamination. ${ }^{127}$ Therefore, an ideal endodontic obturation material should not only possess adequate physicochemical properties, such as dimensional stability, radiopacity, moisture resistance and non-toxicity, but it should also exhibit some antimicrobial properties against potential surviving bacteria in the root canal. ${ }^{128,129}$ Furthermore, bioactivity and remineralization potential may provide additional benefits for root canal obturation materials by strengthening root dentine and promoting formation of hard tissue. ${ }^{130}$ However, the most commonly used obturation material, gutta-percha, is characteristically inert, whilst commercially available endodontic sealers also present with a range of drawbacks, including provisional antimicrobial activity and lack of adhesion to the root dentine. ${ }^{128,131,132}$ In order to overcome the various limitations, researchers have turned to nanoparticles as a means to improve existing sealers as well as develop new ones.

\section{Quaternary Ammonium Compounds}

Quaternary ammonium compounds have been explored as antibacterial compounds in restorative dental materials and also as components of root canal sealers. ${ }^{133,134}$ In particular, quaternary ammonium polyethyleneimine (QPEI) is a polycationic disinfectant that has demonstrated broad spectrum antimicrobial and antibiofilm properties via electrostatic interaction with bacterial cell membranes, leading to cell damage and leakage of cellular constituents. ${ }^{135}$ QPEI nanoparticles are also unique in that they are able to induce intracellular signals that lead to programmed cell death. ${ }^{6}$ Furthermore, these compounds are capable of offering long-term antimicrobial effects due to their insoluble nature. ${ }^{133}$ When incorporated into epoxy resin-based sealers, the addition of QPEI nanoparticles was found to enhance the sealer's antibacterial activity. $^{134,136-138}$ It has been suggested that QPEI nanoparticles improve the bactericidal action of sealers by not only directly disrupting membrane integrity, but also indirectly acting on distant regions of biofilms, although the exact mechanism has yet to be elucidated. ${ }^{137,139}$ The addition of QPEI nanoparticles into $\mathrm{AH} \mathrm{Plus}^{\mathrm{TM}}$, an epoxy resin-based sealer, and Pulp Canal Sealer ${ }^{\mathrm{TM}}$, a zinc oxide eugenol-based sealer, was also found to modulate osteoblast and osteoclast growth and differentiation by regulating intracellular signalling pathways, with the degree of impact depending on the concentration, bone cell type and sealer used. ${ }^{140}$ Furthermore, studies have shown the possibility of combining commercially available sealers and QPEI nanoparticles without having detrimental effects on sealer cytotoxicity and the physicochemical properties, such as solubility, flow, compressive strength and dimensional stability. ${ }^{134,140,141}$ However, it has been reported that the incorporation of QPEI nanoparticles led to no significant improvement in the antibacterial efficacy of AH Plus ${ }^{\mathrm{TM}}{ }^{141}$ Another study reported that the antibiofilm effects against $E$. faecalis of QPEI nanoparticle-modified AH Plus ${ }^{\mathrm{TM}}$ may be strain-dependent. ${ }^{142}$ In contrast, the addition of QPEI nanoparticles to Pulp Canal Sealer ${ }^{\mathrm{TM}}$ improved the antibacterial and antibiofilm efficacy against E. faecalis. ${ }^{141,142}$ Contradicting results between studies may be attributed to differences in experimental protocols $^{143}$ or as a consequence of interferences with the base sealer constituents. ${ }^{141,142}$ Furthermore, although the addition of QPEI nanoparticles to existing root canal sealers may provide a host of different benefits, it is also important to consider the potential drawbacks of this nanomaterial, such as polymerization shrinkage, solvent sorption, altered mechanical properties and cytotoxicity. ${ }^{144}$

Several studies have been dedicated to formulating novel endodontic sealers based on quaternary ammonium methacrylates. Dimethylaminohexadecyl methacrylate (DMAHDM) is a long-chain chemical variant that can be immobilized in a resin matrix upon the formation of bonds via free radical polymerization, hence leading to prolonged 
antibacterial potency via penetration and disruption of bacterial membranes upon contact. ${ }^{145}$ With the addition of other antimicrobial nanoparticles, synergistic effects may be able to enhance the antibacterial activity and remineralization potential of these novel root canal sealers. A study found the combination of AgNPs and DMAHDM in a novel endodontic sealer showed promising antibiofilm efficacy against $E$. faecalis, as the novel sealer reduced the biofilm CFU by 6 orders of magnitude more than AH Plus ${ }^{\text {TM }}{ }^{146}$ It has been reported that an experimental sealer containing amorphous calcium phosphate nanoparticles and DMAHDM exhibited antibiofilm activity and high levels of calcium and phosphate ion release, suggesting a potential to encourage remineralization and strengthen compromised root structures. ${ }^{147-149}$ Apart from the development of experimental sealers, another study modified an existing epoxy resin-based sealer using DMAHDM and AgNPs which resulted in improved and prolonged antimicrobial properties. Whilst AH Plus ${ }^{\mathrm{TM}}$ lost its antibacterial efficacy by day 7 , the modified sealer retained its antibacterial properties for up to 14 days. ${ }^{150}$

\section{Nanostructured Silver Vanadate with AgNPs}

As previously discussed, AgNPs possess potent antimicrobial properties, however concerns have been raised regarding their tendency to aggregate. Hence, to maximize their potential application as endodontic sealers, nanostructured silver vanadate has been suggested as a means to stabilize AgNPs. ${ }^{151,152}$ The incorporation of nanostructured silver vanadate with AgNPs into endodontic sealers appeared to have no dire effects on the physicochemical properties. ${ }^{153}$ However, conflicting results have been published regarding its effects on the antibacterial activity of sealers. One study reported that there was no additional antibacterial benefit gained when the sealers were in a freshly mixed state, ${ }^{154}$ whilst another reported enhanced antibacterial properties in both freshly mixed and set states. ${ }^{155}$ Furthermore, the extent of benefit from the inclusion of silver vanadate nanowires decorated with AgNPs may depend on the type of commercial sealer and the concentration used. ${ }^{156}$ It has been suggested that only higher concentrations of these compounds enhance the antimicrobial activity of sealers, thus more clinically relevant experiments should be carried out to ascertain the extent of the benefits against the costs, such as cytotoxicity and tooth discolouration. ${ }^{143}$

\section{Zinc Oxide Nanoparticles}

ZnONPs have likewise been used to formulate novel endodontic sealers or modify existing zinc oxide eugenol sealers in order to improve physicochemical and antibacterial properties. ${ }^{157,158}$ One of the first studies to highlight the potential uses of nanoparticles in endodontics incorporated ZnONPs, with or without chitosan nanoparticles, into a zinc oxide eugenol-based sealer, which resulted in improved antibacterial properties. ${ }^{158}$ Obturation with gutta-percha and nano-zinc oxide eugenol sealer resulted in less apical microleakage compared to $\mathrm{AH} 26^{\mathrm{TM}}$ and micro-zinc oxide eugenol sealer. ${ }^{157}$ The cytotoxic effects of nano-zinc oxide eugenol sealer were reported to be not more than that of other commercially available sealers, such as AH $26^{\mathrm{TM}}$ and Pulpdent ${ }^{\mathrm{TM}} \cdot{ }^{159}$ When incorporated into polyethylene tubes implanted in rats, nano-zinc oxide eugenol sealer instigated similar tissue reactions compared to Pulp Canal Sealer ${ }^{\mathrm{TM}}$ and AH $26^{\mathrm{TM}} \cdot{ }^{160}$ Versiani et al modified a zinc oxide eugenol sealer with different amounts of ZnONPs and found that replacing $25 \%$ of zinc oxide powder with ZnONPs resulted in improved physicochemical properties, such as dimensional stability, flowability, radiopacity and solubility. ${ }^{161}$ A recent study combined ZnONPs and AgNPs with an experimental urethane acrylate composite sealer which resulted in better antibacterial activity at lower concentrations compared to when either of the nanoparticles were added independently. ${ }^{162}$

\section{Chitosan Nanoparticles}

As prior mentioned, given that the antibacterial properties of chitosan nanoparticles are time and contact-dependent, these nano-biopolymers certainly have potential to be formulated into novel antibacterial endodontic sealers. ${ }^{64,65,68}$ Several studies have explored the possibility of using chitosan nanoparticles to modify existing zinc oxide eugenol sealers which improved their antibacterial and antibiofilm efficacy. ${ }^{68,158}$ A combination of chitosan nanoparticles and ZnONPs improved the antibiofilm efficacy of a calcium hydroxide-based sealer, Apexit Plus ${ }^{\mathrm{TM}}$, however only the sealer modified with ZnONPs was effective against the endodontic isolate strain of E. faecalis. ${ }^{163}$ It has been reported that the incorporation of chitosan nanoparticles into ThermaSeal Plus ${ }^{\mathrm{TM}}$, an epoxy resin-based sealer, promoted its antibacterial efficacy. ${ }^{67}$ However, when added to MTA fillapex ${ }^{\mathrm{TM}}$, a calcium silicate-based sealer, the same extent of improvements was not observed. ${ }^{67} \mathrm{~A}$ possible 
explanation for the varying results is the dissimilar physicochemical properties of different sealers which may interfere with or dampen any additional antibacterial benefit from chitosan nanoparticles. ${ }^{67}$

\section{Other Nanoparticle-Based Modifications of Obturation Materials and Sealers}

Polymeric nanoparticle carriers have also been used to modify endodontic obturation materials and sealers so as to improve the sustained and temporal release of antimicrobial compounds whilst reducing the toxicity of these compounds in their free form. ${ }^{164}$ For example, an experimental root canal sealer that incorporated propolis-loaded PLGA nanoparticles resulted in antimicrobial effects against E. faecalis, Streptococcus mutans and Candida albicans. ${ }^{165}$ Recently, the application of doxycyclinefunctionalized PolymP- $n$ Active nanoparticles was found to occlude dentinal tubules and exert antibiofilm effects against E. faecalis. ${ }^{166}$

Apart from antibacterial efficacy, nanoparticle-based modifications have been used to enhance other physicochemical properties of endodontic sealers, including bioactivity and radiopacity. One study found the inclusion of bioactive glass and hydroxyapatite nanoparticles enhanced the bioactivity of an epoxy resin-based sealer. ${ }^{167}$ Another study reported mesoporous calcium silicate nanoparticles could provide multiple functions as a potential root filling material including drug delivery, bioactivity and osteostimulation. ${ }^{168}$ In order to enhance the radiopacity of Portland cement-based sealers, Viapiana et al incorporated either niobium oxide or zirconium dioxide in microor nanoparticle forms. However, the modified sealers were not sufficiently radiopaque according to the specifications set by the International Organization for Standardization. ${ }^{169,170}$

Lastly, several studies have investigated nanoparticulate modifications to gutta-percha. An in vitro study reported that nanodiamond-embedded gutta-percha functionalized with amoxicillin introduced antibacterial properties to this originally inert obturation material. ${ }^{171}$ Following that, a clinical study used nanodiamond-embedded gutta-percha to obturate the middle third of root canals and observed no adverse effects and no difference in healing outcome compared to the control up to a period of 6 months. ${ }^{172}$ As with most of these innovations, further research is required to determine the optimal concentration and tailor the synthesis of nanoparticle-based obturation materials so as to deliver adequate antimicrobial efficacy without compromising the physicochemical properties.

\section{Regenerative Endodontic Strategies}

Conventional endodontic treatment concerns the cleaning, shaping and obturation of root canal systems. However, since the pioneering report by Banchs and Trope, more researchers have shifted their focus towards regenerative therapies. ${ }^{173}$ These strategies aim to restore the form and function of a tooth by eliminating infection, promoting the development and closure of immature root apices and reestablishing pulpal vitality. ${ }^{99,173}$ Tissue engineering and biological procedures that involve stem cells, bioactive molecules and scaffolds form the basis of regenerative endodontics. $^{174}$

Nanoparticle-based carrier systems have been proposed as a method for the sustained release of bioactive molecules, ${ }^{175,176}$ which are a crucial component of regenerative endodontics as they modulate cellular activity, such as proliferation, migration and differentiation. ${ }^{177}$ As nanoparticles possess enhanced solubility, high surface-area-tovolume ratio and minute dimensions, nanoparticle-based carrier systems may improve the dissolution and absorption of bioactive molecules and drugs. ${ }^{176}$ Several polymeric nanocarriers have been investigated in the context of conventional root canal treatment, such as those previously discussed including chitosan, PLGA and PolymP$n$ Active nanoparticles, ${ }^{107,165,166}$ as well as regenerative therapies. ${ }^{178-182}$ Bovine serum albumin-loaded chitosan nanoparticles were found to improve the viability of stem cells from the apical papilla (SCAP) and enhance alkaline phosphatase activity. ${ }^{180}$ Dexamethasone-loaded chitosan nanoparticles were able to improve the odontogenic differentiation of SCAP. ${ }^{181}$ Dentine conditioning with either chitosan nanoparticles or dexamethasone-modified chitosan nanoparticles also had the potential to mitigate the deleterious impacts of $\mathrm{NaOCl}$ and LPS, whilst stimulating SCAP adherence, viability and differentiation. ${ }^{179,182}$ The sustained release of dexamethasone encapsulated by poly ( $\varepsilon$-caprolactone)-forsterite nanocomposite fibrous membranes has been reported to promote osteogenic differentiation and proliferation of stem cells from human exfoliated deciduous teeth. ${ }^{178}$

Nanoparticles have also been customized to develop various forms of scaffolds, which are another key component of regenerative endodontic therapies. Scaffolds are temporary structures that mimic the extra-cellular matrix to support the growth and differentiation of stem cells and 
aid the controlled release of drugs and bioactive molecules. ${ }^{183}$ They can also be combined with nanocarriers to allow multiple bioactive molecule releasing mechanisms. ${ }^{175}$ By taking advantage of chitosan's ability to adapt and swell to fit the configuration of different sites and its readiness to be conjugated with other molecules, ${ }^{184}$ Bellamy et al reported that a carboxymethyl chitosanbased scaffold with transforming growth factor- $\beta 1$-loaded chitosan nanoparticles was able enhance the viability, differentiation and migration of SCAP. ${ }^{185}$ Similarly, it has been demonstrated that odontogenic differentiation of human dental pulp cells can also be stimulated by the incorporation of dexamethasone and bioactive glass nanoparticles into a nanofiber scaffold system. ${ }^{186}$ The addition of bioactive glass nanoparticles may improve the mechanical properties of scaffolds whilst promoting bioactivity and mineralization via the release and deposition of calcium. ${ }^{187}$ Another study used cellulose nanocrystals to reinforce hydrogel scaffolds, resulting in increased stiffness and stability. The reinforced hydrogel was also laced with platelet lysate, which is rich in proangiogenic and chemotactic factors and has the potential to enhance the revascularization and regeneration of pulpal tissue. ${ }^{188}$

Lastly, nanoparticles have also been used in novel methods for the assessment of regenerative outcomes. Biz et al complexed gold nanoparticles and a biodegradable organic plastic, L-lysine, to create compounds that would be readily internalized by stem cells. The study found that the resultant increase in cell radiopacity could allow for microtomography to identity the presence of viable cells after regenerative procedures without apparent deleterious cytotoxic effects. ${ }^{189}$

\section{Potential Adverse Effects of Nanoparticles}

When investigating the potential translational applications of nanoparticles, attention must be given to the possible adverse effects. ${ }^{31}$ Nanotoxicology has hence emerged as a field of study focused on evaluating the hazards associated with nanomaterial exposure. ${ }^{190}$ The characteristics responsible for nanoparticles' unique properties are also responsible for their potential toxicity to oral tissues, systemic health and the environment. ${ }^{191}$ The extent of toxicity depends on a myriad of factors, such as the material, concentration, duration of exposure, aggregation, particle size, geometry and surface charge. ${ }^{2}$

\section{Effects on Oral Tissues}

Nanoparticle-based endodontic therapies are not without disadvantages, such as the potential for cytotoxic effects to periapical and pulpal tissues. As previously mentioned, the application of AgNPs has been met with reservations due to potential cytotoxicity. ${ }^{192}$ The cytotoxicity of AgNPsbased irrigants on rat tissue was reported to be concentration-dependent, as more persistent inflammation was associated with the application of a $47 \mathrm{ppm}$ AgNPs dispersion when compared to $23 \mathrm{ppm} .{ }^{54}$ These findings were echoed by another study that reported AgNPs in low concentrations were minimally cytotoxic to L929 murine fibroblasts. ${ }^{36}$ AgNPs-based irrigation solutions were reported to be less cytotoxic than conventional endodontic irrigants, such as $3 \% \mathrm{NaOCl}$ and $17 \%$ EDTA, to human gingival fibroblasts. ${ }^{57}$ The extent of cytotoxicity indeed depends on the material, as more favourable interactions have been associated with chitosan nanoparticles. ${ }^{193}$ Shrestha et al found that these naturally occurring biopolymers exhibited no cytotoxicity to both macrophages ${ }^{88}$ and fibroblasts. ${ }^{85}$ Photoactivated rose bengal-conjugated chitosan likewise showed low levels of cytotoxicity. ${ }^{85,88}$ Furthermore, special efforts should be made to ensure the biocompatibility of novel nanoparticle-based endodontic obturation materials and intracanal medicaments, given the possibility of extrusion beyond the apex and direct contact with the periapical tissues. ${ }^{20,128}$ For instance, the widely used intracanal medicament calcium hydroxide is known for being cytotoxic to periapical tissues, ${ }^{194}$ however its nanoparticle equivalents were not found to be significantly less cytotoxic. ${ }^{100}$ A novel endodontic sealer incorporating QPEI nanoparticles was reported to have favourable biocompatibility, with no observed lysis of L929 fibroblasts. ${ }^{134}$ Similarly, a mesoporous calcium silicate nanoparticle-based root filling material had no cytotoxic effects to periodontal ligament cells and even encouraged osteogenic properties by modulating gene expression. $^{168}$

\section{Effects on Systemic Health}

There are multiple routes that may allow the entry of nanoparticles into the human body, including the lungs, skin, gastrointestinal tract and systemic administration. ${ }^{191}$ Given that nanoparticles have similar dimensions to biological molecules, they are readily absorbed by various organs and tissues, and have been found to accumulate in the lungs, liver and reticuloendothelial system. ${ }^{195-197}$ 
Toxic concentrations can cause damage by both reactive oxygen species-dependent and independent mechanisms. ${ }^{198}$ Oxidative stress may have a significant role in causing tissue damage by instigating DNA mutations, cytokine release, protein denaturation, lipid peroxidation and cell apoptosis. ${ }^{190,191}$ For example, AgNPs have been reported to induce inflammation in the lungs and damage alveoli. ${ }^{199}$ When exposed to peripheral blood mononuclear cells, AgNPs at high concentrations were found to be potentially cytotoxic and could modulate cytokine expression. ${ }^{200}$ The organic biopolymer chitosan, on the other hand, is generally considered to be non-toxic and biocompatible. ${ }^{61}$ However, it has been suggested that greater cytotoxicity is associated with smaller particle sizes and higher concentrations. ${ }^{201}$ QPEI nanoparticles, another frequently investigated organic nanomaterial in dentistry, were incorporated into restorative materials and reported to exert no adverse effects on macrophage viability. $^{202}$ These examples highlight the importance of a full understanding of the potential hazardous health effects of nanoparticle applications in endodontics before clinical research is undertaken.

\section{Environmental Effects}

There also exists environmental concerns associated with the use of nanoparticles. ${ }^{58}$ Nanoparticles may act as pollutants and accumulate in the environment and, given that the toxic effects are often concentration-dependent, bioaccumulation could result in subsequent systemic toxicity to exposed living organisms. ${ }^{203}$ A level of uncertainty exists regarding the ideal policies for proper recycling and safe disposal of nanoparticles, as the extent of the harmful effects from their biopersistence has yet to be fully elucidated. $^{2}$

Overall, the potential adverse effects of the application of nanoparticles in endodontics must not be overlooked as they could impact treatment success, patient health and the environment. $^{31}$ It is important to thoroughly investigate the extent of potential harm and ascertain safe methods of application to minimize the biological and environmental risk whilst maximizing the therapeutic benefit.

\section{Conclusion}

The advances in nanotechnology may lead to a new era of translational applications of nanoparticles in endodontic treatment. The current literature suggests that nanoparticles may be developed for a variety of purposes in endodontics, such as disinfection strategies, photodynamic therapy, obturation materials and regenerative procedures. Nonetheless, nanoparticles should not be applied with a "one size fits all" approach, given that different materials, formulations and combinations will generate different properties, both beneficial and adverse. Thus, nanoparticle applications in endodontics have a lot of potential but there is still some way to go before the basic research translates to clinical studies.

\section{Acknowledgments}

This work was supported by Seed Fund for Basic Research (201910159019) and Platform Technology Funding from The University of Hong Kong to CF ZHANG.

\section{Disclosure}

The authors declare that they have no conflicts of interest in this work.

\section{References}

1. European Commission. Commission recommendation of 18 October 2011 on the definition of nanomaterial. Published 2011. Available from: http://data.europa.eu/eli/reco/2011/696/oj. Accessed 10 Oct, 2020

2. Jeevanandam J, Barhoum A, Chan YS, Dufresne A, Danquah MK. Review on nanoparticles and nanostructured materials: history, sources, toxicity and regulations. Beilstein J Nanotechnol. 2018;9:1050-1074. doi:10.3762/bjnano.9.98

3. Khan I, Saeed K, Khan I. Nanoparticles: properties, applications and toxicities. Arab J Chem. 2019;12(7):908-931. doi:10.1016/j. arabjc.2017.05.011

4. Rai MK, Deshmukh SD, Ingle AP, Gade AK. Silver nanoparticles: the powerful nanoweapon against multidrug-resistant bacteria. J Appl Microbiol. 2012;112(5):841-852. doi:10.1111/ j.1365-2672.2012.05253.x

5. Sanvicens N, Marco MP. Multifunctional nanoparticles-properties and prospects for their use in human medicine. Trends Biotechnol. 2008;26(8):425-433. doi:10.1016/j.tibtech.2008.04.005

6. Beyth N, Houri-Haddad Y, Domb A, Khan W, Hazan R. Alternative antimicrobial approach: nano-antimicrobial materials. Evid Based Complement Alternat Med. 2015;2015:246012. doi:10.1155/2015/246012

7. Bapat RA, Chaubal TV, Joshi CP, et al. An overview of application of silver nanoparticles for biomaterials in dentistry. Mater Sci Eng C Mater Biol Appl. 2018;91:881-898. doi:10.1016/j. msec.2018.05.069

8. Rabea EI, Badawy ME, Stevens CV, Smagghe G, Steurbaut W. Chitosan as antimicrobial agent: applications and mode of action. Biomacromolecules. 2003;4(6):1457-1465. doi:10.1021/bm034130m

9. Freitas RA. Nanodentistry. $J$ Am Dent Assoc. 2000;131 (11):1559-1565. doi:10.14219/jada.archive.2000.0084

10. Yin IX, Zhang J, Zhao IS, Mei ML, Li Q, Chu CH. The antibacterial mechanism of silver nanoparticles and its application in dentistry. Int J Nanomedicine. 2020;15:2555-2562. doi:10.2147/ IJN.S246764

11. Nair PN. Light and electron microscopic studies of root canal flora and periapical lesions. $J$ Endod. 1987;13(1):29-39. doi:10.1016/S0099-2399(87)80089-4 
12. Ricucci D, Siqueira JF. Biofilms and apical periodontitis: study of prevalence and association with clinical and histopathologic findings. $J$ Endod. 2010;36(8):1277-1288. doi:10.1016/j. joen.2010.04.007

13. Marsh PD. Dental plaque as a microbial biofilm. Caries Res. 2004;38(3):204-211. doi:10.1159/000077756

14. Wilson M. Susceptibility of oral bacterial biofilms to antimicrobial agents. J Med Microbiol. 1996;44(2):79-87. doi:10.1099/ 00222615-44-2-79

15. Ricucci D, Siqueira Jr. JF. Fate of the tissue in lateral canals and apical ramifications in response to pathologic conditions and treatment procedures. J Endod. 2010;36(1):1-15. doi:10.1016/j. joen.2009.09.038

16. Wong DT, Cheung GS. Extension of bactericidal effect of sodium hypochlorite into dentinal tubules. J Endod. 2014;40(6):825-829. doi:10.1016/j.joen.2013.09.045

17. Stuart CH, Schwartz SA, Beeson TJ, Owatz CB. Enterococcus faecalis: its role in root canal treatment failure and current concepts in retreatment. $J$ Endod. 2006;32(2):93-98. doi:10.1016/j. joen.2005.10.049

18. Love RM. Enterococcus faecalis-a mechanism for its role in endodontic failure. Int Endod J. 2001;34(5):399-405. doi:10.1046/j.1365-2591.2001.00437.x

19. Zehnder M. Root canal irrigants. J Endod. 2006;32(5):389-398. doi:10.1016/j.joen.2005.09.014

20. Dutner J, Mines P, Anderson A. Irrigation trends among American association of endodontists members: a web-based survey. J Endod. 2012;38(1):37-40. doi:10.1016/j.joen.2011.08.013

21. Byström A, Sundqvist G. Bacteriologic evaluation of the effect of 0.5 percent sodium hypochlorite in endodontic therapy. Oral Surg Oral Med Oral Pathol. 1983;55(3):307-312. doi:10.1016/00304220(83)90333-X

22. Hasselgren G, Olsson B, Cvek M. Effects of calcium hydroxide and sodium hypochlorite on the dissolution of necrotic porcine muscle tissue. J Endod. 1988;14(3):125-127. doi:10.1016/S00992399(88)80212-7

23. Marending M, Luder HU, Brunner TJ, Knecht S, Stark WJ, Zehnder M. Effect of sodium hypochlorite on human root dentine-mechanical, chemical and structural evaluation. Int Endod J. 2007;40(10):786-793. doi:10.1111/j.1365-2591.2007.01287.x

24. Hülsmann M, Hahn W. Complications during root canal irrigation - literature review and case reports. Int Endod J. 2000;33 (3):186-193. doi:10.1046/j.1365-2591.2000.00303.x

25. Evans M, Davies JK, Sundqvist G, Figdor D. Mechanisms involved in the resistance of Enterococcus faecalis to calcium hydroxide. Aust Dent J. 2001;27(3):115.

26. Naenni N, Thoma K, Zehnder M. Soft tissue dissolution capacity of currently used and potential endodontic irrigants. J Endod. 2004;30(11):785-787. doi:10.1097/00004770-200411000-00009

27. Ringel AM, Patterson SS, Newton CW, Miller CH, Mulhern JM. In vivo evaluation of chlorhexidine gluconate solution and sodium hypochlorite solution as root canal irrigants. J Endod. 1982;8(5):200-204. doi:10.1016/S0099-2399(82)80354-3

28. Garberoglio R, Becce C. Smear layer removal by root canal irrigants. A comparative scanning electron microscopic study. Oral Surg Oral Med Oral Pathol. 1994;78(3):359-367. doi:10.1016/0030-4220(94)90069-8

29. Ozdemir HO, Buzoglu HD, Calt S, Stabholz A, Steinberg D. Effect of ethylenediaminetetraacetic acid and sodium hypochlorite irrigation on Enterococcus faecalis biofilm colonization in young and old human root canal dentin: in vitro study. $J$ Endod. 2010;36(5):842-846. doi:10.1016/j.joen.2010.01.008

30. Niu W, Yoshioka T, Kobayashi C, Suda H. A scanning electron microscopic study of dentinal erosion by final irrigation with EDTA and NaOCl solutions. Int Endod J. 2002;35(11):934-939. doi:10.1046/j.1365-2591.2002.00594.x
31. Samiei M, Ghasemi N, Divband B, Balaei E, Hosien Soroush Barhaghi M, Divband A. Antibacterial efficacy of polymer containing nanoparticles in comparison with sodium hypochlorite in infected root canals. Minerva Stomatol. 2015;64(6):275-281.

32. Ipe DS, Kumar PTS, Love RM, Hamlet SM. Silver nanoparticles at biocompatible dosage synergistically increases bacterial susceptibility to antibiotics. Front Microbiol. 2020;11:1074. doi:10.3389/fmicb.2020.01074

33. Panáček A, Smékalová M, Kilianová M, et al. Strong and nonspecific synergistic antibacterial efficiency of antibiotics combined with silver nanoparticles at very low concentrations showing no cytotoxic effect. Molecules. 2015;21(1):26. doi:10.3390/molecules21010026

34. Patra JK, Baek KH. Antibacterial activity and synergistic antibacterial potential of biosynthesized silver nanoparticles against foodborne pathogenic bacteria along with its anticandidal and antioxidant effects. Front Microbiol. 2017;8:167. doi:10.3389/ fmicb.2017.00167

35. Panáček A, Kvítek L, Smékalová M, et al. Bacterial resistance to silver nanoparticles and how to overcome it. Nat Nanotechnol. 2018;13(1):65-71. doi:10.1038/s41565-017-0013-y

36. Abbaszadegan A, Nabavizadeh M, Gholami A, et al. Positively charged imidazolium-based ionic liquid-protected silver nanoparticles: a promising disinfectant in root canal treatment. Int Endod J. 2015;48(8):790-800. doi:10.1111/iej.12377

37. Wu D, Fan W, Kishen A, Gutmann JL, Fan B. Evaluation of the antibacterial efficacy of silver nanoparticles against Enterococcus faecalis biofilm. J Endod. 2014;40(2):285-290. doi:10.1016/j. joen.2013.08.022

38. Halkai KR, Mudda JA, Shivanna V, Rathod V, Halkai R. Evaluation of antibacterial efficacy of fungal-derived silver nanoparticles against Enterococcus faecalis. Contemp Clin Dent. 2018;9(1):45-48. doi:10.4103/ccd.ccd_828_17

39. Chávez-Andrade GM, Tanomaru-Filho M, Basso Bernardi MI, de Toledo Leonardo R, Faria G, Guerreiro-Tanomaru JM. Antimicrobial and biofilm anti-adhesion activities of silver nanoparticles and farnesol against endodontic microorganisms for possible application in root canal treatment. Arch Oral Biol. 2019;107:104481. doi:10.1016/j.archoralbio.2019.104481

40. Ioannidis K, Niazi S, Mylonas P, Mannocci F, Deb S. The synthesis of nano silver-graphene oxide system and its efficacy against endodontic biofilms using a novel tooth model. Dent Mater. 2019;35(11):1614-1629. doi:10.1016/j.dental.2019.08.105

41. Kushwaha V, Yadav RK, Tikku AP, et al. Comparative evaluation of antibacterial effect of nanoparticles and lasers against Endodontic Microbiota: an in vitro study. J Clin Exp Dent. 2018;10(12):1155-1160. doi:10.4317/jced.55076

42. de Almeida J, Cechella BC, Bernardi AV, de Lima Pimenta A, Felippe WT. Effectiveness of nanoparticles solutions and conventional endodontic irrigants against Enterococcus faecalis biofilm. Indian J Dent Res. 2018;29(3):347-351. doi:10.4103/ijdr. IJDR_634_15

43. Halkai KR, Halkai R, Mudda JA, Shivanna V, Rathod V. Antibiofilm efficacy of biosynthesized silver nanoparticles against endodontic-periodontal pathogens: an in vitro study. J Conserv Dent. 2018;21(6):662-666. doi:10.4103/JCD.JCD_203_18

44. Rodrigues CT, de Andrade FB, de Vasconcelos $\bar{L}$, et al. Antibacterial properties of silver nanoparticles as a root canal irrigant against Enterococcus faecalis biofilm and infected dentinal tubules. Int Endod J. 2018;51(8):901-911. doi:10.1111/ iej. 12904

45. Das MR, Sarma RK, Saikia R, Kale VS, Shelke MV, Sengupta P. Synthesis of silver nanoparticles in an aqueous suspension of graphene oxide sheets and its antimicrobial activity. Colloids Surf B Biointerfaces. 2011;83(1):16-22. doi:10.1016/j. colsurfb.2010.10.033 
46. He J, Zhu X, Qi Z, et al. Killing dental pathogens using antibacterial graphene oxide. ACS Appl Mater Interfaces. 2015;7 (9):5605-5611. doi:10.1021/acsami.5b01069

47. Jowkar Z, Hamidi SA, Shafiei F, Ghahramani Y. The effect of silver, zinc oxide, and titanium dioxide nanoparticles used as final irrigation solutions on the fracture resistance of root-filled teeth. Clin Cosmet Investig Dent. 2020;12:141-148. doi:10.2147/ CCIDE.S253251

48. Farshad M, Abbaszadegan A, Ghahramani Y, Jamshidzadeh A. Effect of imidazolium-based silver nanoparticles on root dentin roughness in comparison with three common root canal irrigants. Iran Endod J. 2017;12(1):83-86. doi:10.22037/iej.2017.17

49. Suzuki TYU, Gallego J, Assunção WG, Briso ALF, Dos Santos PH. Influence of silver nanoparticle solution on the mechanical properties of resin cements and intrarradicular dentin. PLoS One. 2019;14(6):e0217750. doi:10.1371/journal. pone. 0217750

50. Suzuki TYU, Pereira MA, Gomes-Filho JE, Wang L, Assunção WG, Santos PHD. Do irrigation solutions influence the bond interface between glass fiber posts and dentin? Braz Dent J. 2019;30(2):106-116. doi:10.1590/0103-6440201901963

51. Moazami F, Sahebi S, Ahzan S. Tooth discoloration induced by imidazolium based silver nanoparticles as an intracanal irrigant J Dent (Shiraz). 2018;19(4):280-286.

52. Ahamed M, Karns M, Goodson M, et al. DNA damage response to different surface chemistry of silver nanoparticles in mammalian cells. Toxicol Appl Pharmacol. 2008;233(3):404-410. doi:10.1016/j.taap.2008.09.015

53. Jana NR, Patra PK, Saha A, Basiruddin SK, Pradhan N. Imidazole based biocompatible polymer coating in deriving $<25$ $\mathrm{nm}$ functional nanoparticle probe for cellular imaging and detection. J Phys Chem C. 2009;113(52):21484-21492.

54. Gomes-Filho JE, Silva FO, Watanabe S, et al. Tissue reaction to silver nanoparticles dispersion as an alternative irrigating solution. $J$ Endod. 2010;36(10):1698-1702. doi:10.1016/j.joen.2010.07.007

55. Nabavizadeh M, Ghahramani Y, Abbaszadegan A, Jamshidzadeh A, Jenabi P, Makarempour A. In vivo biocompatibility of an ionic liquid-protected silver nanoparticle solution as root canal irrigant. Iran Endod J. 2018;13(3):293-298. doi:10.22037/iej.v13i3.17386

56. Chávez-Andrade GM, Tanomaru-Filho M, Rodrigues EM, et al. Cytotoxicity, genotoxicity and antibacterial activity of poly(vinyl alcohol)-coated silver nanoparticles and farnesol as irrigating solutions. Arch Oral Biol. 2017;84:89-93. doi:10.1016/j. archoralbio.2017.09.028

57. Ertem E, Gutt B, Zuber F, et al. Core-shell silver nanoparticles in endodontic disinfection solutions enable long-term antimicrobial effect on oral biofilms. ACS Appl Mater Interfaces. 2017;9 (40):34762-34772. doi:10.1021/acsami.7b13929

58. Scientific Committee on Emerging and Newly Identified Health Risks of the European Commission. The appropriateness of existing methodologies to assess the potential risks associated with engineered and adventitious products of nanotechnologies. Published 2006. Available from: https://ec.europa.eu/health/ph risk/committees/04 scenihr/docs/scenihr_o 003b.pdf. Accessed Dec 31, 2020.

59. Scientific Committee on Emerging and Newly Identified Health Risks of the European Commission. Scientific basis for the definition of the term nanomaterial. Published 2010. Available from: https://ec.europa.eu/health/scientific_committees/opinions_lay man/nanomaterials2012/de/1-3/2.htm\#0. Accessed Jan 3, 2020.

60. Kong M, Chen XG, Xing K, Park HJ. Antimicrobial properties of chitosan and mode of action: a state of the art review. Int J Food Microbiol. 2010;144(1):51-63. doi:10.1016/j ijfoodmicro.2010.09.012
61. Dutta PK, Dutta J, Tripathi VS. Chitin and chitosan: chemistry, properties and applications. $J$ Sci Ind Res. 2004;63:20-31.

62. Del Carpio-Perochena A, Bramante CM, Duarte MA, de Moura MR, Aouada FA, Kishen A. Chelating and antibacterial properties of chitosan nanoparticles on dentin. Restor Dent Endod. 2015;40(3):195-201. doi:10.5395/rde.2015.40.3.195

63. Ionescu A, Harris D, Selvaganapathy PR, Kishen A Electrokinetic transport and distribution of antibacterial nanoparticles for endodontic disinfection. Int Endod J. 2020;53 (8):1120-1130. doi:10.1111/iej.13321

64. Shrestha A, Shi Z, Neoh KG, Kishen A. Nanoparticulates for antibiofilm treatment and effect of aging on its antibacterial activity. J Endod. 2010;36(6):1030-1035. doi:10.1016/j.joen.2010.02.008

65. Upadya M, Shrestha A, Kishen A. Role of efflux pump inhibitors on the antibiofilm efficacy of calcium hydroxide, chitosan nanoparticles, and light-activated disinfection. J Endod. 2011;37 (10):1422-1426. doi:10.1016/j.joen.2011.06.017

66. Shrestha A, Kishen A. The effect of tissue inhibitors on the antibacterial activity of chitosan nanoparticles and photodynamic therapy. J Endod. 2012;38(9):1275-1278. doi:10.1016/j.joen.2012.05.006

67. Del Carpio-Perochena A, Kishen A, Shrestha A, Bramante CM. Antibacterial properties associated with chitosan nanoparticle treatment on root dentin and 2 types of endodontic sealers. J Endod. 2015;41(8):1353-1358. doi:10.1016/j.joen.2015.03.020

68. DaSilva L, Finer Y, Friedman S, Basrani B, Kishen A. Biofilm formation within the interface of bovine root dentin treated with conjugated chitosan and sealer containing chitosan nanoparticles. $J$ Endod. 2013;39(2):249-253. doi:10.1016/j.joen.2012.11.008

69. Roshdy NN, Kataia EM, Helmy NA. Assessment of antibacterial activity of $2.5 \% \mathrm{NaOCl}$, chitosan nano-particles against Enterococcus faecalis contaminating root canals with and without diode laser irradiation: an in vitro study. Acta Odontol Scand. 2019;77(1):39-43. doi:10.1080/00016357.2018.1498125

70. Shrestha A, Fong SW, Khoo BC, Kishen A. Delivery of antibacterial nanoparticles into dentinal tubules using high-intensity focused ultrasound. $J$ Endod. 2009;35(7):1028-1033. doi:10.1016/j.joen.2009.04.015

71. Li FC, Borkar S, Ramachandran A, Kishen A. Novel activated microbubbles-based strategy to coat nanoparticles on root canal dentin: fluid dynamical characterization. $J$ Endod. 2019;45 (6):797-802. doi:10.1016/j.joen.2019.02.011

72. Silva PV, Guedes DF, Nakadi FV, Pecora JD, Cruz-Filho AM. Chitosan: a new solution for removal of smear layer after root canal instrumentation. Int Endod J. 2013;46(4):332-338. doi:10.1111/j.1365-2591.2012.02119.x

73. Hashmi A, Sodhi RNS, Kishen A. Interfacial characterization of dentin conditioned with chitosan hydroxyapatite precursor nanocomplexes using time-of-flight secondary ion mass spectrometry. JEndod. 2019;45(12):1513-1521. doi:10.1016/j.joen.2019.08.011

74. Kishen A, Shrestha S, Shrestha A, Cheng C, Goh C. Characterizing the collagen stabilizing effect of crosslinked chitosan nanoparticles against collagenase degradation. Dent Mater. 2016;32(8):968-977. doi:10.1016/j.dental.2016.05.005

75. Aydın ZU, Özyürek T, Keskin B, Baran T. Effect of chitosan nanoparticle, QMix, and EDTA on TotalFill BC sealers' dentinal tubule penetration: a confocal laser scanning microscopy study. Odontology. 2019;107(1):64-71. doi:10.1007/s10266-018-0359-0

76. Ratih DN, Sari NI, Santosa P, Kaswati NMN. Time-dependent effect of chitosan nanoparticles as final irrigation on the apical sealing ability and push-out bond strength of root canal obturation. Int J Dent. 2020;2020:1-6. doi:10.1155/2020/8887593

77. Yavari H, Ghasemi N, Divband B, Rezaei Y, Jabbari G, Payahoo S. The effect of photodynamic therapy and polymer solution containing nano-particles of $\mathrm{Ag} / \mathrm{ZnO}$ on push-out bond strength of the sealers AH-Plus and MTA Fillapex. J Clin Exp Dent. 2017;9(9):e1109-e1114. doi:10.4317/jced.54069 
78. Monzavi A, Eshraghi S, Hashemian R, Momen-Heravi F. In vitro and ex vivo antimicrobial efficacy of nano-MgO in the elimination of endodontic pathogens. Clin Oral Investig. 2015;19 (2):349-356. doi:10.1007/s00784-014-1253-y

79. Bukhari S, Kim D, Liu Y, Karabucak B, Koo H. Novel endodontic disinfection approach using catalytic nanoparticles. J Endod. 2018;44(5):806-812. doi:10.1016/j.joen.2017.12.003

80. Hu X, Zhang Y, Ding T, Liu J, Zhao H. Multifunctional gold nanoparticles: a novel nanomaterial for various medical applications and biological activities. Front Bioeng Biotechnol. 2020;8:990. doi:10.3389/fbioe.2020.00990

81. Arafa MG, El-Kased RF, Elmazar MM. Thermoresponsive gels containing gold nanoparticles as smart antibacterial and wound healing agents. Sci Rep. 2018;8(1):13674. doi:10.1038/s41598018-31895-4

82. Dougherty TJ, Gomer CJ, Henderson BW, et al. Photodynamic therapy. J Natl Cancer Inst. 1998;90(12):889-905. doi:10.1093/ jnci/90.12.889

83. Afkhami F, Akbari S, Chiniforush N. Entrococcus faecalis elimination in root canals using silver nanoparticles, photodynamic therapy, diode laser, or laser-activated nanoparticles: an in vitro study. $J$ Endod. 2017;43(2):279-282. doi:10.1016/j. joen.2016.08.029

84. Camacho-Alonso F, Julián-Belmonte E, Chiva-García F, Martínez-Beneyto Y. Bactericidal efficacy of photodynamic therapy and chitosan in root canals experimentally infected with enterococcus faecalis: an in vitro study. Photomed Laser Surg. 2017;35(4):184-189. doi:10.1089/pho.2016.4148

85. Shrestha A, Hamblin MR, Kishen A. Characterization of a conjugate between Rose Bengal and chitosan for targeted antibiofilm and tissue stabilization effects as a potential treatment of infected dentin. Antimicrob Agents Chemother. 2012;56 (9):4876-4884. doi:10.1128/AAC.00810-12

86. Neelakantan P, Romero $M$, Vera J, et al. Biofilms in endodontics-current status and future directions. Int J Mol Sci. 2017;18(8):1748. doi:10.3390/ijms 18081748

87. Ruenraroengsak P, Cook JM, Florence AT. Nanosystem drug targeting: facing up to complex realities. J Control Release. 2010;141(3):265-276. doi:10.1016/j.jconrel.2009.10.032

88. Shrestha A, Cordova M, Kishen A. Photoactivated polycationic bioactive chitosan nanoparticles inactivate bacterial endotoxins. J Endod. 2015;41(5):686-691. doi:10.1016/j.joen.2014.12.007

89. Shrestha A, Friedman S, Torneck CD, Kishen A. Bioactivity of photoactivated functionalized nanoparticles assessed in lipopolysaccharide-contaminated root canals in vivo. $J$ Endod. 2018;44(1):104-110. doi:10.1016/j.joen.2017.08.021

90. Shrestha A, Kishen A. Antibacterial efficacy of photosensitizer functionalized biopolymeric nanoparticles in the presence of tissue inhibitors in root canal. $J$ Endod. 2014;40(4):566-570. doi:10.1016/j.joen.2013.09.013

91. Akbari T, Pourhajibagher M, Hosseini F, et al. The effect of indocyanine green loaded on a novel nano-graphene oxide for high performance of photodynamic therapy against Enterococcus faecalis. Photodiagnosis Photodyn Ther. 2017;20:148-153. doi:10.1016/j.pdpdt.2017.08.017

92. Li FC, Nicholson E, Singh CV, Kishen A. Microtissue engineering root dentin with photodynamically cross-linked nanoparticles improves fatigue resistance of endodontically treated teeth. J Endod. 2020;46(5):668-674. doi:10.1016/j.joen.2020.01.021

93. Musthalib S, Verma AH, Sundar S, Sampath Kumar TS, Velmurugan N, Krithikadatta J. Evaluation of effect of two different functionalized nanoparticle photodynamic therapy on nanohardness of root dentin-an in vitro study. Photodiagnosis Photodyn Ther. 2020;31:101856. doi:10.1016/j.pdpdt.2020.101856
94. Persadmehr A, Torneck CD, Cvitkovitch DG, et al. Bioactive chitosan nanoparticles and photodynamic therapy inhibit collagen degradation in vitro. J Endod. 2014;40(5):703-709. doi:10.1016/j. joen.2013.11.004

95. Byström A, Sunvqvist G. The antibacterial action of sodium hypochlorite and EDTA in 60 cases of endodontic therapy. Int Endod J. 1985;18(1):35-40. doi:10.1111/j.1365-2591.1985. tb00416.x

96. Sjögren U, Figdor D, Spångberg L, Sundqvist G. The antimicrobial effect of calcium hydroxide as a short-term intracanal dressing. Int Endod J. 1991;24(3):119-125. doi:10.1111/j.13652591.1991.tb00117.x

97. Zancan RF, Calefi PHS, Borges MMB, et al. Antimicrobial activity of intracanal medications against both Enterococcus faecalis and Candida albicans biofilm. Microsc Res Tech. 2019;82 (5):494-500. doi:10.1002/jemt.23192

98. Andreasen JO, Farik B, Munksgaard EC. Long-term calcium hydroxide as a root canal dressing may increase risk of root fracture. Dent Traumatol. 2002;18(3):134-137. doi:10.1034/ j.1600-9657.2002.00097.x

99. Galler KM, Krastl G, Simon S, et al. European Society of Endodontology position statement: revitalization procedures. Int Endod J. 2016;49(8):717-723. doi:10.1111/iej.12629

100. Dianat O, Saedi S, Kazem M, Alam M. Antimicrobial activity of nanoparticle calcium hydroxide against Enterococcus faecalis: an in vitro study. Iran Endod J. 2015;10(1):39-43.

101. Sireesha A, Jayasree R, Vidhya S, Mahalaxmi S, Sujatha V, Kumar TSS. Comparative evaluation of micron- and nano-sized intracanal medicaments on penetration and fracture resistance of root dentin - an in vitro study. Int J Biol Macromol. 2017;104(Pt B):1866-1873. doi:10.1016/j.ijbiomac.2017.05.126

102. Louwakul P, Saelo A, Khemaleelakul S. Efficacy of calcium oxide and calcium hydroxide nanoparticles on the elimination of Enterococcus faecalis in human root dentin. Clin Oral Investig. 2017;21(3):865-871. doi:10.1007/s00784-016-1836-x

103. Zand V, Mokhtari H, Hasani A, Jabbari G. Comparison of the penetration depth of conventional and nano-particle calcium hydroxide into dentinal tubules. Iran Endod J. 2017;12 (3):366-370. doi:10.22037/iej.v12i3.16421

104. Naseri M, Eftekhar L, Gholami F, Atai M, Dianat O. The effect of calcium hydroxide and nano-calcium hydroxide on microhardness and superficial chemical structure of root canal dentin: an ex vivo study. J Endod. 2019;45(9):1148-1154. doi:10.1016/j.joen.2019.06.002

105. Dianat O, Azadnia S, Mozayeni MA. Toxicity of calcium hydroxide nanoparticles on murine fibroblast cell line. Iran Endod J. 2015;10(1):49-54.

106. Balto H, Bukhary S, Al-Omran O, BaHammam A, Al-Mutairi B. Combined effect of a mixture of silver nanoparticles and calcium hydroxide against Enterococcus faecalis biofilm. $J$ Endod. 2020;46(11):1689-1694. doi:10.1016/j.joen.2020.07.001

107. Makkar H, Patri G. Fabrication and appraisal of poly (lactic-coglycolic acid) - moxifloxacin nanoparticles using vitamin E-TPGS: a potential intracanal drug delivery agent. $J$ Clin Diagn Res. 2017;11(6):05-08.

108. Fava LR, Saunders WP. Calcium hydroxide pastes: classification and clinical indications. Int Endod J. 1999;32(4):257-282.

109. Bruniera JF, Silva-Sousa YT, Lara MG, Pitondo-Silva A, Marcaccini AM, Miranda CE. Development of intracanal formulation containing silver nanoparticles. Braz Dent J. 2014;25 (4):302-306. doi:10.1590/0103-6440201302431

110. Mozayeni MA, Hadian A, Bakhshaei P, Dianat O. Comparison of antifungal activity of $2 \%$ chlorhexidine, calcium hydroxide, and nanosilver gels against Candida Albicans. J Dent (Tehran). 2015;12(2):109-117. 
111. Samiei M, Torab A, Hosseini O, Abbasi T, Abdollahi AA, Divband B. Antibacterial effect of two nano zinc oxide gel preparations compared to calcium hydroxide and chlorhexidine mixture. Iran Endod J. 2018;13(3):305-311. doi:10.22037/iej.v13i3.19866

112. Afkhami F, Pourhashemi SJ, Sadegh M, Salehi Y, Fard MJ. Antibiofilm efficacy of silver nanoparticles as a vehicle for calcium hydroxide medicament against Enterococcus faecalis. J Dent. 2015;43(12):1573-1579. doi:10.1016/j.jdent.2015.08.012

113. Javidi M, Afkhami F, Zarei M, Ghazvini K, Rajabi O. Efficacy of a combined nanoparticulate/calcium hydroxide root canal medication on elimination of Enterococcus faecalis. Aust Endod J. 2014;40(2):61-65. doi:10.1111/aej.12028

114. Zhang FH, Li M, Wei ZJ, Zhao B. The effect of a combined nanoparticulate/calcium hydroxide medication on the biofilm of Enterococcus faecalis in starvation phase. Shanghai Kou Qiang Yi Xue. 2016;25(1):11-15.

115. Afkhami F, Elahy S, Mahmoudi-Nahavandi A. Spectrophotometric analysis of crown discoloration following the use of silver nanoparticles combined with calcium hydroxide as intracanal medicament. J Clin Exp Dent. 2017;9(7):e842-e847.

116. Guerreiro-Tanomaru JM, Pereira KF, Nascimento CA, Bernardi MI, Tanomaru-Filho M. Use of nanoparticulate zinc oxide as intracanal medication in endodontics: $\mathrm{pH}$ and antimicrobial activity. Acta Odontol Latinoam. 2013;26(3):144-148.

117. Aguiar AS, Guerreiro-Tanomaru JM, Faria G, Leonardo RT, Tanomaru-Filho M. Antimicrobial activity and ph of calcium hydroxide and zinc oxide nanoparticles intracanal medication and association with chlorhexidine. J Contemp Dent Pract. 2015;16(8):624-629. doi:10.5005/jp-journals-10024-1732

118. Fan W, Wu C, Han P, Zhou Y, Xiao Y. Porous Ca-Si-based nanospheres: a potential intra-canal disinfectant-carrier for infected canal treatment. Mater Lett. 2012;81:16-19. doi:10.1016/j.matlet.2012.04.142

119. Fan W, Wu D, Tay FR, Ma T, Wu Y, Fan B. Effects of adsorbed and templated nanosilver in mesoporous calcium-silicate nanoparticles on inhibition of bacteria colonization of dentin. Int J Nanomedicine. 2014;9:5217-5230. doi:10.2147/IJN.S73144

120. Fan W, Wu Y, Ma T, Li Y, Fan B. Substantivity of Ag-Ca-Si mesoporous nanoparticles on dentin and its ability to inhibit Enterococcus faecalis. J Mater Sci Mater Med. 2016;27(1):16. doi:10.1007/s10856-015-5633-x

121. Leng D, Li Y, Zhu J, et al. The Antibiofilm activity and mechanism of nanosilver- and nanozinc-incorporated mesoporous calcium-silicate nanoparticles. Int $J$ Nanomedicine. 2020;15:3921-3936. doi:10.2147/IJN.S244686

122. Zhu J, Liang R, Sun C, et al. Effects of nanosilver and nanozinc incorporated mesoporous calcium-silicate nanoparticles on the mechanical properties of dentin. PLoS One. 2017;12(8):1-16. doi:10.1371/journal.pone.0182583

123. Fan W, Wu D, Ma T, Fan B. Ag-loaded mesoporous bioactive glasses against Enterococcus faecalis biofilm in root canal of human teeth. Dent Mater J. 2015;34(1):54-60. doi:10.4012/ dmj.2014-104

124. Waltimo T, Mohn D, Paqué F, et al. Fine-tuning of bioactive glass for root canal disinfection. J Dent Res. 2009;88(3):235-238. doi:10.1177/0022034508330315

125. Marending M, Stark WJ, Brunner TJ, Fischer J, Zehnder M. Comparative assessment of time-related bioactive glass and calcium hydroxide effects on mechanical properties of human root dentin. Dent Traumatol. 2009;25(1):126-129. doi:10.1111/j.16009657.2008.00735.x

126. Mohn D, Zehnder M, Imfeld T, Stark WJ. Radio-opaque nanosized bioactive glass for potential root canal application: evaluation of radiopacity, bioactivity and alkaline capacity. Int Endod J. 2010;43(3):210-217. doi:10.1111/j.13652591.2009.01660.x
127. Ørstavik D. Endodontic Treatment of Apical Periodontitis. In: Ørstavik D, editor. Essential Endodontology. 3rd ed. John Wiley \& Sons Ltd; 2020:313-343.

128. Ørstavik DAG. Materials used for root canal obturation: technical, biological and clinical testing. Endod Topics. 2005;12 (1):25-38. doi:10.1111/j.1601-1546.2005.00197.x

129. Grossman LI. Physical properties of root canal cements. $J$ Endod. 1976;2(6):166-175. doi:10.1016/S0099-2399(76) 80059-3

130. Parirokh M, Torabinejad M. Mineral trioxide aggregate: a comprehensive literature review-part III: clinical applications, drawbacks, and mechanism of action. J Endod. 2010;36 (3):400-413. doi:10.1016/j.joen.2009.09.009

131. Baumgartner G, Zehnder M, Paqué F. Enterococcus faecalis type strain leakage through root canals filled with gutta-percha/AH plus or Resilon/Epiphany. $J$ Endod. 2007;33(1):45-47. doi:10.1016/j.joen.2006.08.002

132. Pizzo G, Giammanco G, Cumbo E, Nicolosi G, Gallina G. In vitro antibacterial activity of endodontic sealers. $J$ Dent. 2006;34:35-40. doi:10.1016/j.jdent.2005.03.001

133. Beyth N, Yudovin-Farber I, Bahir R, Domb AJ, Weiss EI. Antibacterial activity of dental composites containing quaternary ammonium polyethylenimine nanoparticles against Streptococcus mutans. Biomaterials. 2006;27(21):3995-4002. doi:10.1016/j. biomaterials.2006.03.003

134. Beyth N, Kesler Shvero D, Zaltsman N, et al. Rapid kill-novel endodontic sealer and Enterococcus faecalis. PLoS One. 2013;8(11):78586. doi:10.1371/journal.pone.0078586

135. Lan T, Guo Q, Shen X. Polyethyleneimine and quaternized ammonium polyethyleneimine: the versatile materials for combating bacteria and biofilms. J Biomater Sci Polym Ed. 2019;30(14):1243-1259. doi:10.1080/09205063.2019. 1627650

136. Abramovitz I, Wisblech D, Zaltsman N, Weiss EI, Beyth N. intratubular antibacterial effect of polyethyleneimine nanoparticles: an ex vivo study in human teeth. $J$ Nanomater. 2015;2015:1-5. doi:10.1155/2015/980529

137. Kesler Shvero D, Abramovitz I, Zaltsman N, Perez Davidi M, Weiss EI, Beyth N. Towards antibacterial endodontic sealers using quaternary ammonium nanoparticles. Int Endod J. 2013;46(8):747-754. doi:10.1111/iej.12054

138. Zaltsman N, Kesler-Shvero D, Weiss EI, Beyth N. Synthesis variants of quaternary ammonium polyethyleneimine nanoparticles and their antibacterial efficacy in dental materials. $J$ Appl Biomater Funct Mater. 2016;14(2):205-211.

139. Kesler Shvero D, Zaltsman N, Weiss EI, Polak D, Hazan R, Beyth N. Lethal bacterial trap: cationic surface for endodontic sealing. J Biomed Mater Res A. 2016;104(2):427-434. doi:10.1002/jbm.a.35576

140. Barros J, Costa-Rodrigues J, Lopes MA, Pina-Vaz I, Fernandes MH. Response of human osteoblastic and osteoclastic cells to $\mathrm{AH}$ plus and pulp canal sealer containing quaternary ammonium polyethylenimine nanoparticles. J Endod. 2014;40 (8):1149-1155. doi:10.1016/j.joen.2014.03.022

141. Barros J, Silva MG, Rodrigues MA, et al. Antibacterial, physicochemical and mechanical properties of endodontic sealers containing quaternary ammonium polyethylenimine nanoparticles. Int Endod J. 2014;47(8):725-734. doi:10.1111/iej.12207

142. Barros J, Silva MG, Rôças IN, et al. Antibiofilm effects of endodontic sealers containing quaternary ammonium polyethylenimine nanoparticles. $J$ Endod. 2014;40(8):1167-1171. doi:10.1016/j.joen.2013.12.021

143. Brezhnev A, Neelakantan P, Tanaka R, Brezhnev S, Fokas G, Matinlinna JP. Antibacterial additives in epoxy resin-based root canal sealers: a focused review. Dent $J$ (Basel). 2019;7(3):72. doi:10.3390/dj7030072 
144. Makvandi P, Jamaledin R, Jabbari M, Nikfarjam N, Borzacchiello A. Antibacterial quaternary ammonium compounds in dental materials: a systematic review. Dent Mater. 2018;34 (6):851-867. doi:10.1016/j.dental.2018.03.014

145. Li F, Weir MD, Xu HH. Effects of quaternary ammonium chain length on antibacterial bonding agents. J Dent Res. 2013;92 (10):932-938. doi:10.1177/0022034513502053

146. Baras BH, Melo MAS, Sun J, et al. Novel endodontic sealer with dual strategies of dimethylaminohexadecyl methacrylate and nanoparticles of silver to inhibit root canal biofilms. Dent Mater. 2019;35(8):1117-1129. doi:10.1016/j.dental.2019.05.014

147. Baras BH, Wang S, Melo MAS, et al. Novel bioactive root canal sealer with antibiofilm and remineralization properties. J Dent. 2019;83:67-76. doi:10.1016/j.jdent.2019.02.006

148. Baras BH, Sun J, Melo MAS, et al. Novel root canal sealer with dimethylaminohexadecyl methacrylate, nano-silver and nano-calcium phosphate to kill bacteria inside root dentin and increase dentin hardness. Dent Mater. 2019;35(10):1479-1489. doi:10.1016/j.dental.2019.07.014

149. Wang L, Xie X, Li C, et al. Novel bioactive root canal sealer to inhibit endodontic multispecies biofilms with remineralizing calcium phosphate ions. J Dent. 2017;60:25-35. doi:10.1016/j. jdent.2017.02.011

150. Seung J, Weir MD, Melo MAS, et al. A modified resin sealer: physical and antibacterial properties. $J$ Endod. 2018;44 (10):1553-1557. doi:10.1016/j.joen.2018.06.016

151. Holtz RD, Lima BA, Souza Filho AG, Brocchi M, Alves OL. Nanostructured silver vanadate as a promising antibacterial additive to water-based paints. Nanomedicine. 2012;8(6):935-940. doi:10.1016/j.nano.2011.11.012

152. Correa JM, Mori M, Sanches HL, da Cruz AD, Poiate E, Poiate IA. Silver nanoparticles in dental biomaterials. Int J Biomater. 2015;2015:485275. doi:10.1155/2015/485275

153. Teixeira A, Vidal C, Tornavoi D, Oliveira-Santos C, Schiavon M, Reis A. Incorporating antimicrobial nanomaterial and its effect on the antimicrobial activity, flow and radiopacity of endodontic sealers. Eur Endod J. 2017;2(1):1-6. doi:10.14744/ eej.2017.16029

154. Vilela Teixeira AB, de Carvalho Honorato Silva C, Alves OL, Cândido Dos Reis A. Endodontic sealers modified with silver vanadate: antibacterial, compositional, and setting time evaluation. Biomed Res Int. 2019;2019(1):1-9. doi:10.1155/ 2019/4676354

155. Teixeira AB, Vidal C, Albiasetti T, Castro D, Reis A. Influence of adding nanoparticles of silver vanadate on antibacterial effect and physicochemical properties of endodontic sealers. Iran Endod J. 2019;14:7-13.

156. Vilela Teixeira AB, Vidal CL, de Castro DT, et al. Effect of incorporation of a new antimicrobial nanomaterial on the physical-chemical properties of endodontic sealers. J Conserv Dent. 2017;20(6):392-397. doi:10.4103/JCD.JCD_266_17

157. Javidi M, Zarei M, Naghavi N, Mortazavi M, Nejat AH. Zinc oxide nano-particles as sealer in endodontics and its sealing ability. Contemp Clin Dent. 2014;5(1):20-24. doi:10.4103/0976237X.128656

158. Kishen A, Shi Z, Shrestha A, Neoh KG. An investigation on the antibacterial and antibiofilm efficacy of cationic nanoparticulates for root canal disinfection. J Endod. 2008;34(12):1515-1520. doi:10.1016/j.joen.2008.08.035

159. Javidi M, Zarei M, Omidi S, Ghorbani A, Gharechahi M, Shayani Rad M. Cytotoxicity of a new nano zinc-oxide eugenol sealer on murine fibroblasts. Iran Endod J. 2015;10(4):231-235. doi:10.7508/iej.2015.04.004
160. Omidi S, Javidi M, Zarei M, Mushakhian S, Jafarian A. Subcutaneous connective tissue reaction to a new nano zinc-oxide eugenol sealer in rat model. Iran Endod J. 2017;12 (1):64-69. doi:10.22037/iej.2017.13

161. Versiani MA, Abi Rached-Junior FJ, Kishen A, Pécora JD, SilvaSousa YT, de Sousa-neto MD. Zinc oxide nanoparticles enhance physicochemical characteristics of grossman sealer. $J$ Endod. 2016;42(12):1804-1810. doi:10.1016/j.joen.2016.08.023

162. Chang HH, Tseng YT, Huang SW, et al. Evaluation of carbon dioxide-based urethane acrylate composites for sealers of root canal obturation. Polymers (Basel). 2020;12(2):482. doi:10.3390/polym12020482

163. Nair N, James B, Devadathan A, Johny MK, Mathew J, Jacob J. Comparative evaluation of antibiofilm efficacy of chitosan nanoparticle- and zinc oxide nanoparticle-incorporated calcium hydroxide-based sealer: an in vitro study. Contemp Clin Dent. 2018;9(3):434-439. doi:10.4103/ccd.ccd_225_18

164. De Jong WH, Borm PJA. Drug delivery and nanoparticles: applications and hazards. Int J Nanomedicine. 2008;3(2):133-149. doi:10.2147/IJN.S596

165. Abdel Raheem IA, Abdul Razek A, Elgendy AA, Saleh NM, Shaaban MI, Abd El-Hady FK. Design, evaluation and antimicrobial activity of egyptian propolis-loaded nanoparticles: intrinsic role as a novel and naturally based root canal nanosealer. Int $J$ Nanomedicine. 2019;14:8379-8398. doi:10.2147/IJN. S219577

166. Arias-Moliz T, Baca P, Solana C, et al. Doxycycline functionalized polymeric nanoparticles inhibit Enterococcus faecalis biofilm formation on dentine. Int Endod J. 2020. doi:10.1111/ iej. 13436

167. Jerri Al-Bakhsh BA, Shafiei F, Hashemian A, Shekofteh K, Bolhari B, Behroozibakhsh M. In-vitro bioactivity evaluation and physical properties of an epoxy-based dental sealer reinforced with synthesized fluorine-substituted hydroxyapatite, hydroxyapatite and bioactive glass nanofillers. Bioact Mater. 2019;4:322-333. doi:10.1016/j.bioactmat.2019.10.004

168. Wu C, Chang J, Fan W. Bioactive mesoporous calcium-silicate nanoparticles with excellent mineralization ability, osteostimulation, drug-delivery and antibacterial properties for filling apex roots of teeth. $J$ Mater Chem. 2012;22(33):16801-16809. doi:10.1039/c2jm33387b

169. Viapiana R, Flumignan DL, Guerreiro-Tanomaru JM, Camilleri J, Tanomaru-Filho M. Physicochemical and mechanical properties of zirconium oxide and niobium oxide modified Portland cement-based experimental endodontic sealers. Int Endod J. 2014;47(5):437-448. doi:10.1111/iej.12167

170. International Organization for Standardization. ISO 6876:2012 Dentistry — Root Canal Sealing Materials. 3rd ed. 2012.

171. Lee D-K, Kim S, Limansubroto A, et al. Nanodiamond-gutta percha composite biomaterials for root canal therapy. ACS Nano. 2015;9:11490-11501. doi:10.1021/acsnano.5b05718

172. Lee $\mathrm{DK}$, Kee $\mathrm{T}$, Liang $\mathrm{Z}$, et al. Clinical validation of a nanodiamond-embedded thermoplastic biomaterial. Proc Natl Acad Sci U S A. 2017;114(45):E9445-e9454. doi:10.1073/ pnas.1711924114

173. Banchs F, Trope M. Revascularization of immature permanent teeth with apical periodontitis: new treatment protocol? $J \quad$ Endod. 2004;30(4):196-200. doi:10.1097/00004770200404000-00003

174. Murray PE, Garcia-Godoy F, Hargreaves KM. Regenerative endodontics: a review of current status and a call for action. J Endod. 2007;33(4):377-390. doi:10.1016/j.joen.2006.09.013 
175. Shrestha S, Kishen A. Bioactive molecule delivery systems for dentin-pulp tissue Engineering. J Endod. 2017;43(5):733-744. doi:10.1016/j.joen.2016.12.020

176. Kishen A, Hussein H. Bioactive molecule carrier systems in endodontics. Expert Opin Drug Deliv. 2020;17(8):1093-1112. doi:10.1080/17425247.2020.1777981

177. Lee K, Silva EA, Mooney DJ. Growth factor delivery-based tissue engineering: general approaches and a review of recent developments. $J \quad R$ Soc Interface. 2011;8(55):153-170. doi:10.1098/rsif.2010.0223

178. Kharaziha M, Fathi MH, Edris H, Nourbakhsh N, Talebi A, Salmanizadeh S. PCL-forsterite nanocomposite fibrous membranes for controlled release of dexamethasone. J Mater Sci Mater Med. 2015;26(1):5364. doi:10.1007/s10856-014-5364-4

179. Kukreti H, Li FC, Singh K, Sodhi R, Kishen A. Efficacy of bioactive nanoparticles on tissue-endotoxin induced suppression of stem cell viability, migration and differentiation. Int Endod J. 2020;53(6):859-870. doi:10.1111/iej.13283

180. Shrestha S, Diogenes A, Kishen A. Temporal-controlled release of bovine serum albumin from chitosan nanoparticles: effect on the regulation of alkaline phosphatase activity in stem cells from apical papilla. J Endod. 2014;40(9):1349-1354. doi:10.1016/j. joen.2014.02.018

181. Shrestha S, Diogenes A, Kishen A. Temporal-controlled dexamethasone releasing chitosan nanoparticle system enhances odontogenic differentiation of stem cells from apical papilla. J Endod. 2015;41(8):1253-1258. doi:10.1016/j.joen.2015.03.024

182. Shrestha S, Torneck CD, Kishen A. Dentin conditioning with bioactive molecule releasing nanoparticle system enhances adherence, viability, and differentiation of stem cells from apical papilla. $J$ Endod. 2016;42(5):717-723. doi:10.1016/j. joen.2016.01.026

183. Bae H, Puranik AS, Gauvin R, et al. Building vascular networks. Sci Transl Med. 2012;4(160):160ps123. doi:10.1126/ scitranslmed.3003688

184. Bernkop-Schnürch A. Chitosan and its derivatives: potential excipients for peroral peptide delivery systems. Int J Pharm. 2000;194(1):1-13. doi:10.1016/S0378-5173(99)00365-8

185. Bellamy C, Shrestha S, Torneck C, Kishen A. Effects of a bioactive scaffold containing a sustained transforming growth factor- $\beta 1$-releasing nanoparticle system on the migration and differentiation of stem cells from the apical papilla. $J$ Endod. 2016;42(9):1385-1392. doi:10.1016/j.joen.2016.06.017

186. Lim HC, Nam OH, Kim MJ, et al. Delivery of dexamethasone from bioactive nanofiber matrices stimulates odontogenesis of human dental pulp cells through integrin/BMP/mTOR signaling pathways. Int J Nanomedicine. 2016;11:2557-2567. doi:10.2147/ IJN.S97846

187. Moonesi Rad R, Atila D, Akgün EE, Evis Z, Keskin D, Tezcaner A. Evaluation of human dental pulp stem cells behavior on a novel nanobiocomposite scaffold prepared for regenerative endodontics. Mater Sci Eng C Mater Biol Appl. 2019;100:928-948. doi:10.1016/j.msec.2019.03.022

188. Silva CR, Babo PS, Gulino M, et al. Injectable and tunable hyaluronic acid hydrogels releasing chemotactic and angiogenic growth factors for endodontic regeneration. Acta Biomater. 2018;77:155-171. doi:10.1016/j.actbio.2018.07.035

189. Biz MT, Cucco C, Cavalcanti BN. Incorporation of AuNP-PLL nanocomplexes in DPSC: a new tool for $3 \mathrm{D}$ analysis in pulp regeneration. Clin Oral Investig. 2020;24(5):1761-1767. doi:10.1007/s00784-019-03037-1
190. Oberdörster G, Oberdörster E, Oberdörster J. Nanotoxicology: an emerging discipline evolving from studies of ultrafine particles. Environ Health Perspect. 2005;113(7):823-839. doi:10.1289/ ehp.7339

191. Nel A, Xia T, Mädler L, Li N. Toxic potential of materials at the nanolevel. Science. 2006;311(5761):622-627. doi:10.1126/ science. 1114397

192. Stensberg MC, Wei Q, McLamore ES, Porterfield DM, Wei A, Sepúlveda MS. Toxicological studies on silver nanoparticles: challenges and opportunities in assessment, monitoring and imaging. Nanomedicine (London, England). 2011;6(5):879-898. doi:10.2217/nnm.11.78

193. Wang JJ, Zeng ZW, Xiao RZ, et al. Recent advances of chitosan nanoparticles as drug carriers. Int $J$ Nanomedicine. 2011;6:765-774. doi:10.2147/IJN.S17296

194. Beltes P, Koulaouzidou E, Kotoula V, Kortsaris AH. In vitro evaluation of the cytotoxicity of calcium hydroxide-based root canal sealers. Endod Dent Traumatol. 1995;11(5):245-249. doi:10.1111/j.1600-9657.1995.tb00497.x

195. Lu X, Zhu T, Chen C, Liu Y. Right or left: the role of nanoparticles in pulmonary diseases. Int $J$ Mol Sci. 2014;15 (10):17577-17600. doi:10.3390/ijms151017577

196. Gopee NV, Roberts DW, Webb P, et al. Migration of intradermally injected quantum dots to sentinel organs in mice. Toxicol Sci. 2007;98(1):249-257. doi:10.1093/toxsci/kfm074

197. Balasubramanian SK, Jittiwat J, Manikandan J, Ong C-N, Yu LE, Ong W-Y. Biodistribution of gold nanoparticles and gene expression changes in the liver and spleen after intravenous administration in rats. Biomaterials. 2010;31(8):2034-2042. doi:10.1016/j. biomaterials.2009.11.079

198. Chairuangkitti P, Lawanprasert S, Roytrakul S, et al. Silver nanoparticles induce toxicity in A549 cells via ROS-dependent and ROS-independent pathways. Toxicol in Vitro. 2013;27 (1):330-338. doi:10.1016/j.tiv.2012.08.021

199. Fehaid A, Hamed M, Abo Agglomeration Uelmagd M, Taniguchi A. Time-dependent toxic effect and distribution of silver nanoparticles compared to silver nitrate after intratracheal instillation in rats. Am J of Nanomater. 2016;4:12-19.

200. Shin S-H, Ye M-K, Kim H-S, Kang H-S. The effects of nano-silver on the proliferation and cytokine expression by peripheral blood mononuclear cells. Int Immunopharmacol. 2007;7 (13):1813-1818. doi:10.1016/j.intimp.2007.08.025

201. Omar Zaki SS, Ibrahim MN, Katas H. Particle size affects concentration-dependent cytotoxicity of chitosan nanoparticles towards mouse hematopoietic stem cells. J Nanotechnol. 2015;2015:1-5. doi:10.1155/2015/919658

202. Beyth N, Houri-Haddad Y, Baraness-Hadar L, Yudovin-Farber I, Domb AJ, Weiss EI. Surface antimicrobial activity and biocompatibility of incorporated polyethylenimine nanoparticles. Biomaterials. 2008;29(31):4157-4163. doi:10.1016/j. biomaterials.2008.07.003

203. Dreher KL. Health and environmental impact of nanotechnology: toxicological assessment of manufactured nanoparticles. Toxicol Sci. 2004;77(1):3-5. doi:10.1093/toxsci/kfh041 


\section{Publish your work in this journal}

The International Journal of Nanomedicine is an international, peerreviewed journal focusing on the application of nanotechnology in diagnostics, therapeutics, and drug delivery systems throughout the biomedical field. This journal is indexed on PubMed Central, MedLine, CAS, SciSearch ${ }^{\mathbb{R}}$, Current Contents ${ }^{\mathbb{B}} /$ Clinical Medicine,
Journal Citation Reports/Science Edition, EMBase, Scopus and the Elsevier Bibliographic databases. The manuscript management system is completely online and includes a very quick and fair peer-review system, which is all easy to use. Visit http://www.dovepress.com/ testimonials.php to read real quotes from published authors. 